\title{
Universiteit
}

Leiden

The Netherlands

\section{Early prediction of hospital admission for emergency department patients: a comparison between patients younger or older than 70 years}

Lucke, J.A.; Gelder, J. de; Clarijs, F.; Heringhaus, C.; Craen, A.J.M. de; Fogteloo, A.J.; ... ; Mooijaart, S.P.

\section{Citation}

Lucke, J. A., Gelder, J. de, Clarijs, F., Heringhaus, C., Craen, A. J. M. de, Fogteloo, A. J., ... Mooijaart, S. P. (2018). Early prediction of hospital admission for emergency department patients: a comparison between patients younger or older than 70 years. Emergency Medicine Journal, 35(1), 18-27. doi:10.1136/emermed-2016-205846

Version: $\quad$ Not Applicable (or Unknown)

License: $\quad$ Leiden University Non-exclusive license

Downloaded from: https://hdl.handle.net/1887/76376

Note: To cite this publication please use the final published version (if applicable). 


\section{Emergency Medicine Journal}

\section{Early prediction of hospital admission for emergency department patients, a comparison between patients younger or older than 70-years.}

\begin{tabular}{|c|c|}
\hline Journal: & Emergency Medicine Journal \\
\hline Manuscript ID & emermed-2016-205846.R6 \\
\hline Article Type: & Original article \\
\hline Date Submitted by the Author: & $\mathrm{n} / \mathrm{a}$ \\
\hline Complete List of Authors: & $\begin{array}{l}\text { Lucke, Jacinta; Leiden University Medical Center, Emergency Medicine; } \\
\text { Leiden University Medical Center, Gerontology and Geriatrics } \\
\text { de Gelder, Jelle; Leiden University Medical Center, Gerontology and } \\
\text { Geriatrics } \\
\text { Clarijs, Fleur; Leiden University Medical Center, Emergency Medicine } \\
\text { Heringhaus, Christian; Leiden University Medical Center, Emergency } \\
\text { Medicine } \\
\text { de Craen, Anton; Leiden University Medical Center, Gerontology and } \\
\text { Geriatrics } \\
\text { Fogteloo, Anne; Leiden University Medical Center, Internal Medicine } \\
\text { Blauw, Gerard Jan; Leiden University Medical Center, Gerontology and } \\
\text { Geriatrics; Medical Center Haaglanden - Bronovo, Internal Medicine and } \\
\text { Geriatrics } \\
\text { de Groot, Bas; Leiden University Medical Center, Emergency Medicine } \\
\text { Mooijaart, Simon; Institute for Evidence-based Medicine in Old Age|IEMO, ; } \\
\text { Leiden University Medical Center, Gerontology and Geriatrics }\end{array}$ \\
\hline Keywords: & $\begin{array}{l}\text { geriatrics, hospitalisations, emergency department, aged, research, } \\
\text { epidemiology }\end{array}$ \\
\hline
\end{tabular}


Lucke et al. Early prediction of hospital admission for emergency department patients, a comparison between patients younger or older than 70-years.

\section{TITLEPAGE}

Title

Early prediction of hospital admission for emergency department patients, a comparison between patients younger or older than 70-years.

\section{Authors}

Jacinta A. Lucke, $\mathrm{MD}^{1,2}$; Jelle de Gelder, $\mathrm{MD}^{2}$; Fleur Clarijs, $\mathrm{MD}^{1}$; Christian Heringhaus, $\mathrm{MD}^{1}$; Anton J.M. De Craen, $\mathrm{PhD}^{2,5}$; Anne J. Fogteloo, MD, $\mathrm{PhD}^{3}$; Gerard J. Blauw, MD, $\mathrm{PhD}^{2,6}$; Bas de Groot, MD, $\mathrm{PhD}^{1}$; Simon P. Mooijaart, $\mathrm{MD}, \mathrm{PhD}^{2,4}$

\section{Affiliations}

1. Department of Emergency Medicine, Leiden University Medical Center, Leiden, The Netherlands

2. Department of Gerontology and Geriatrics, Leiden University Medical Center, Leiden, The Netherlands

3. Department of Internal Medicine, Leiden University Medical Center, Leiden, The Netherlands

4. Institute for Evidence-based Medicine in Old Age | IEMO, Leiden, the Netherlands

5. Department of Internal Medicine and Geriatrics, Medical Center Haaglanden-Bronovo, The Hague, The Netherlands

\section{Corresponding author}

Drs. Jacinta A. Lucke, MD

Department of Emergency Medicine K-02-174/

Department of Gerontology and Geriatrics C-07-44

Leiden University Medical Center

Albinusdreef 2, 2333 ZA, Leiden, The Netherlands

Tel: +31715262025/ Fax: +31715248216/ Email: j.a.lucke@lumc.nl

\section{Word count}

3965

Keywords

Geriatrics, hospitalizations, emergency department, aged, research, epidemiology. 
Lucke et al. Early prediction of hospital admission for emergency department patients, a comparison between patients younger or older than 70-years

\section{ABSTRACT}

Objective: The aim of this study was to develop models that predict hospital admission of emergency department patients in patients younger and older than 70 and compare their performance.

Method: Prediction models were derived in a retrospective observational study of all patients $\geq 18$ years-old visiting the emergency department (ED) of a university hospital during the first 6 months of 2012. Patients were stratified into two age groups ( $<70$ years-old, $\geq 70$ years-old). Multivariable logistic regression analysis was used to identify predictors of hospital admission among factors available immediately after patient arrival to the ED. Validation of the prediction models was performed on patients presenting to the ED during the second-half of the year 2012.

Results: 10,807 patients were included in the derivation and 10,480 in the validation cohorts. Strongest independent predictors of hospital admission among the 8,728 patients $<70$ years-old were age, sex, triage category, mode of arrival, performance of blood tests, chief complaint, ED revisit, type of specialist, phlebotomised blood sample, and all vital signs. Area-under-the-curve (AUC) of the validation cohort for those $<70$ years-old was $0.86(95 \% \mathrm{Cl} 0.85-0.87)$. Among the 2,079 patients $\geq 70$ years the same factors were predictive except for gender, type of specialist and heart rate; the AUC was $0.77(95 \% \mathrm{Cl} 0.75-0.79)$. The prediction models could identify a group of $10 \%$ patients with the highest risk in whom hospital admission was predicted at ED triage with a positive predictive value (PPV) of $71 \%(95 \% \mathrm{Cl} 68-74 \%)$ in younger and PPV $87 \%$ $(95 \% \mathrm{Cl} 81-92 \%)$ in older patients.

\section{Conclusion:}

Demographic and clinical factors readily available early in the ED visit can be useful in identifying patients who are likely to be admitted to hospital. While the model for the younger patients had a higher AUC, the model for older patients had a higher PPV in identifying the patients at highest risk for admission. Of note, heart rate was not a useful predictor in the older patients.

\section{Word count abstract: 316}


Lucke et al. Early prediction of hospital admission for emergency department patients, a comparison between patients younger or older than 70-years

\begin{tabular}{|l|l|}
\hline \multicolumn{2}{|c|}{ What this paper adds } \\
\hline \multicolumn{1}{|c|}{ What is already known on this subject } & \multicolumn{1}{c|}{ What this study adds } \\
\hline $\begin{array}{l}\text { (ED) are at risk for hospital admission, functional } \\
\text { decline and mortality, with older patients having } \\
\text { even higher risks. }\end{array}$ & $\begin{array}{l}\text { - The models created in this study indicate that } \\
\text { predictors of hospital admission from the ED are } \\
\text { similar for younger and older patients, but differ in } \\
\text { their prognostic capabilities. The overall prognostic } \\
\text { ability of the models was greater for the patients } \\
\text { under 70, but the model for older patients is better } \\
\text { - Clinical decision making tools for older patients in } \\
\text { the ED have not been found to be effective. }\end{array}$ \\
$\begin{array}{l}\text { - It is unknown whether independent predictors may the a group of patients very likely to be } \\
\text { vary between age groups, which may influence the } \\
\text { design of future tools. }\end{array}$ & $\begin{array}{l}\text { admitted. } \\
\text { creating a screening instrument that could } \\
\text { adequately predict hospital admission, particularly } \\
\text { for older adults. }\end{array}$ \\
\hline
\end{tabular}


Lucke et al. Early prediction of hospital admission for emergency department patients, a comparison between patients younger or older than 70-years

\section{INTRODUCTION}

Older adults presenting to emergency departments (EDs) for medical care frequently are admitted to the hospital[1-4]. Despite a high probability of admission, they are at risk of having prolonged length of stay in the ED, which increases the chance of in-hospital adverse events[5]. If ED physicians had an accurate decision-making tool they could use early during the ED visit to predict which older patients have the highest probability of being admitted using routinely available demographic and clinical factors available at triage, ED length of stay might be reduced. Interventions to expedite the admission of older patients might also improve health-related and ED flow and function outcomes. Such a tool however, is not yet available[6]. It also is not yet known if demographic and clinical factors predictive of hospital admission are the same for both older and younger ED patients, and if decision-making tools comprised of these factors perform equally well for both age groups.

Independent predictors of hospital admission of ED patients have been identified[7] previously, yet mainly reflect disease severity. The Modified Early Warning Score (MEWS)[8] is frequently used to quantify disease severity and can predict probability of hospital admission,[9] disposition[10] and mortality[11] of ED patients. However, physiology, polypharmacy and multiple comorbidities of older patients affect measured vital signs and delay recognition of serious disease; when relying solely on vital signs a proportion of severely ill older patients requiring admission will not be identified[12]. Given the discrepancy in the utility of hospital admission prediction models using vital signs and disease severity when they are applied to different age groups, tools helping to predict need for admission based on other clinical characteristics also might not be equally useful for older and younger ED adult patients. If this is the case, different prediction rules should be derived and used based on patient age.

The goal of this study was therefore to derive prediction models separately for older and younger adults which identify need for hospital admission, using routinely demographic and clinical data available at ED triage. We further aimed to assess how well these prediction models performed for these two age groups. The ultimate aim for this prediction model was for its eventual application in identifying early which patients would be admitted from the ED, potentially improving efficiency of care pathways and reducing ED length of stay. 
Lucke et al. Early prediction of hospital admission for emergency department patients, a comparison between patients younger or older than 70-years

\section{METHOD}

\section{Study design and setting}

This investigation involved deriving and validating a hospital admission prediction rule for adult ED patients. Data were obtained retrospectively from the ED of the Leiden University Medical Center (LUMC), which is a tertiary care hospital with an annual census of approximately 30.000 ED visits. LUMC has an Acute Medical Unit (13 beds) designed to accept admissions from the ED. The Medical Ethics Committee waived the need for informed consent because data were collected as part of past clinical care and de-identified after extraction from the patient files.

\section{Selection of participants}

Inclusion criteria

We included all ED visits by adults $\geq 18$ years-old to LUMC between January 1, 2012 and December 31, 2012. ED patients who presented between January 1 - June 30 were included in the derivation cohort, while those presenting July 1 - December 31 were included in the validation cohort.

\section{Exclusion criteria}

Patients who arrived to the ED undergoing cardiopulmonary resuscitation or classified as Manchester Triage System[13] (MTS) category 'red' (needing immediate care) were excluded because their likelihood of hospital admission was so great that a prediction tool would not be needed for this population. Patients who died in the ED and those who left without being evaluated also were excluded. In addition, patients with ED visits due to logistical reasons were excluded, such as those attending for a planned re-evaluation because they could not wait until the next available out-patient clinic appointment, visits to the ED because of lack of availability of time in the out-patient clinic, laboratory checks for logistical reasons and patients who were sent away from the ED to visit their GP (Figure 1). For this, a pre-defined list of objective criteria, based on expert opinion, was used. Patient files were checked by a single researcher (JAL) to assess exclusion criteria.

\section{Study protocol and measurements}

Data were automatically harvested from the electronic patient files (Chipsoft-EZIS ${ }^{\circledR}$, version 5.2, 2006-2014, Amsterdam, The Netherlands) using an application designed by the LUMC department of Information Technology. One investigator (JAL) checked the data for validity and corrected typing errors. This was performed by reference to medical records in case of outliers. Furthermore using sampling JAL checked patient 
Lucke et al. Early prediction of hospital admission for emergency department patients, a comparison between patients younger or older than 70-years

records to assess if study data was adequately withdrawn from the patients files. The data were not extracted manually and not subject to interpretation. Therefore, a measure of inter-rater variability is not applicable. Because the aim of this investigation was to develop a tool, using data readily available at triage, the following data were collected: age, sex, Manchester Triage System (MTS) triage category, chief complaint, mode of arrival to ED, type of specialist, ED visits within prior 30 days, indication for phlebotomised blood sample testing and vital signs. These variables were chosen by the study authors based on clinical judgement, frequently used variables in similar research[14 15] [16], their availability upon patient arrival to the ED and inclusion in the ED electronic medical records. A detailed description of the collection of all variables can be found in Supplemental Material.

\section{Outcomes}

The primary endpoint of this study was hospital admission, defined as either admission to the LUMC or transfer to another hospital for admission. This outcome was downloaded directly from the patient files.

\section{Data Analysis}

Patients were divided into two age groups for analysis, $<70$ years and $\geq 70$ years-old, in line with the age cut-off used in government initiated interventions in The Netherlands[17]. Data were summarized as number and percentages or means and standard deviation for normally distributed variables, or as medians with interquartile ranges for non-normally distributed variables, as appropriate. Missing measurements of vital signs were handled as a separate category and analysed alongside categories of measured values, for example oxygen saturation has 4 categories: $<90 \%, 91-94 \%, \geq 95 \%$ and missing, where the reference category is $\geq 95 \%$. Student's t-tests assuming independence were used to compare groups for normally distributed variables and Mann-Whitney-U tests for non-normally distributed variables. Chi-square tests were used for categorical variables. Univariable binary logistic regression was used to assess possible predictors of hospital admission using demographic and clinical characteristics extracted from the medical records. Age $(<70$ years-old or $\geq 70$ years-old) as an effect modifier of the relationship between variables in the model and the outcome of hospital admission was tested in the univariable analyses. Multivariable binary logistic regression was used to create an optimal model. Odds Ratios (ORs) and corresponding 95\% confidence intervals (Cls) were estimated. Risks associated with age were expressed per 10 year age groups. The general rule of thumb that at least 10 
Lucke et al. Early prediction of hospital admission for emergency department patients, a comparison between patients younger or older than 70-years

events per predictor variable are needed to prevent over-fitting of the model was used. Because the database contained more than 3000 hospital admissions all potential predictor variables could be incorporated in the model[18].

An optimal model was created for each age group, using backward elimination with Akaike's Information Criterion to eliminate predictors from the model, with a cut-off point of $p<0.05$. This made the model as small as possible whilst still containing all clinically relevant parameters. Goodness of fit was tested using the Hosmer-Lemeshow test, this was performed ten times in a random subsample of 1000 patients.

This method standardized the power of the Hosmer-Lemeshow test to prevent overpowering caused by the large number of study subjects[19].

Receiver operator characteristics curves were drafted and area under the curve (AUC) estimated to measure the discriminative performance of the models. Temporal validation of the models were performed using data collected from the second-half of 2016. Calibration of the models in the validation cohort was assessed using calibration plots.

The distribution of risk of admission per age group was calculated for the validation cohort using the following equation: $\frac{1}{1+\mathrm{e}^{\text {(intercept+linear predictor) }}}$. The individual risk of each patient was calculated and ranked. The $10 \%$ of the ED patient population, per age group, with the highest chance of hospital was designated 'high risk'. This was deemed a clinically relevant and feasible cut-off point for risk of admission, for which sensitivity, specificity, positive predictive value, negative predictive value were calculated.

As a sensitivity analysis, the alternative clinically relevant vital sign cut-off values were assessed as predictors in the models and their discriminative performance and calibration were re-assessed. In a second sensitivity analysis, we created a multivariable model using the whole year 2012 (without dividing the year into successive six-month blocks of time) and randomly selected a training and test cohort to assess for introduction of bias due to the temporal validation.

Statistical significance was set at the alpha $=0.05$ level for all analyses. All statistical analyses were performed using IBM SPSS Statistics package (version 23, New York, USA). 
Lucke et al. Early prediction of hospital admission for emergency department patients, a comparison between patients younger or older than 70-years

\section{RESULTS}

\section{Characteristics of study subjects}

In 2012 , there were 27,862 visits to the LUMC ED, of which 21,287 were included in this analysis (Figure 1 ). The 6575 excluded patients were due to ED use for logistical reasons or arrival during CPR ( $n=1486)$, patients aged $\leq 18$ years $(n=4802)$ or patients with red triage or who deceased $(n=287)$.

Baseline characteristics of the study population stratified by age group are shown in Table 1 . The distribution of demographics and clinical characteristics by age group were similar within the derivation and validation cohorts.

Table 1. Baseline characteristics of study population.

\begin{tabular}{|c|c|c|c|c|c|c|}
\hline \multirow{2}{*}{ Baseline features } & \multicolumn{2}{|c|}{ Derivation } & \multicolumn{4}{|c|}{ Validation } \\
\hline & $\begin{array}{c}<70 \text { years } \\
n=8728\end{array}$ & $\begin{array}{c}\geq 70 \text { years } \\
n=2079\end{array}$ & P value & $\begin{array}{c}<70 \text { years } \\
n=8411\end{array}$ & $\geq 70$ years & P value \\
\hline Age, median IQR & $44.8(28.8-57.4)$ & $78.1(73.9-83.6)$ & & $44.8(28.4-58.0)$ & $77.9(73.9-83.0)$ & \\
\hline Male, $n$ (\%) & $4762(54.6)$ & $995(47.9)$ & $<0.001$ & $4597(54.7)$ & $1044(50.5)$ & 0.001 \\
\hline Triage category, $n$ (\%) & & & $<0.001$ & & & $<0.001$ \\
\hline$<10$ minutes & $1921(22.0)$ & 657 (31.6) & & $1893(22.5)$ & $683(33.0)$ & \\
\hline$<1$ hour & 3567 (40.9) & $943(45.4)$ & & $3557(42.3)$ & 966 (46.7) & \\
\hline$<2$ hour & 3205 (36.7) & $472(22.7)$ & & $2921(34.7)$ & $410(19.8)$ & \\
\hline$<4$ hours & $35(0.4)$ & $7(0.3)$ & & $40(0.5)$ & $10(0.5)$ & \\
\hline Arrival mode, $n$ (\%) & & & $<0.001$ & & & $<0.001$ \\
\hline Self-referral & $4258(48.8)$ & $467(22.5)$ & & $3794(45.1)$ & 404 (19.5) & \\
\hline Ambulance/other institution & $1316(15.1)$ & $596(28.7)$ & & 1659 (19.7) & $833(40.3)$ & \\
\hline Referred by GP/specialist & $3154(36.1)$ & $1016(48.9)$ & & $2958(35.2)$ & $832(40.2)$ & \\
\hline Type of specialist & & & $<0.001$ & & & $<0.001$ \\
\hline Medicine & 3809 (43.6) & $1251(60.2)$ & & 3732 (44.4) & $1245(60.2)$ & \\
\hline Surgery & 4919 (56.4) & $828(39.8)$ & & 4679 (55.6) & $824(39.8)$ & \\
\hline Revisit to the ED, $n$ (\%) & & & 0.082 & & & 0.071 \\
\hline Visit $<30$ days & $922(10.6)$ & 247 (11.9) & & $873(10.4)$ & $243(11.7)$ & \\
\hline Chief complaint $^{1}$ & & & $<0.001$ & & & $<0.001$ \\
\hline Minor trauma & $3656(42.2)$ & $621(30.1)$ & & 3301 (39.6) & $641(31.2)$ & \\
\hline Major trauma & $183(2.1)$ & $32(1.5)$ & & $208(2.5)$ & $28(1.4)$ & \\
\hline Chest pain & $980(11.3)$ & $302(14.6)$ & & 992 (11.9) & $329(16.0)$ & \\
\hline Dyspnea & $426(4.9)$ & $221(10.7)$ & & $394(4.7)$ & $179(8.7)$ & \\
\hline Syncope & $219(2.5)$ & $118(5.7)$ & & $241(2.9)$ & $100(4.9)$ & \\
\hline Psychiatric complaints & $219(2.5)$ & $34(1.6)$ & & $230(2.8)$ & $26(1.3)$ & \\
\hline Malaise & $1032(11.9)$ & 377 (18.3) & & $1034(12.4)$ & 403 (19.6) & \\
\hline Abdominal pain & 935 (10.7) & $183(8.9)$ & & $922(11.1)$ & $183(8.9)$ & \\
\hline Other & $1018(11.7)$ & $177(8.6)$ & & $1019(12.2)$ & $164(8.0)$ & \\
\hline \multicolumn{7}{|l|}{ Vital signs } \\
\hline Systolic BP, mmHg ${ }^{2}$ & $136(21.4)$ & $145(27.3)$ & $<0.001$ & $135(21.5)$ & $145(28.1)$ & $<0.001$ \\
\hline $\mathrm{O}_{2}$ saturation, $\%^{3}$ median, IQR & $98(98-100)$ & $98(96-100)$ & $<0.001$ & $99(97-100)$ & $98(96-99)$ & $<0.001$ \\
\hline Temperature, ${ }^{\circ} \mathrm{C}^{4}$ & $37.0(0.8)$ & $36.9(1.0)$ & $<0.001$ & $37.0(0.8)$ & $36.9(0.9)$ & $<0.001$ \\
\hline
\end{tabular}


Lucke et al. Early prediction of hospital admission for emergency department patients, a comparison between patients younger or older than 70-years

\begin{tabular}{|c|c|c|c|c|c|c|}
\hline Respiratory rate, $/ \mathrm{min}^{5}$ & $17.6(4.6)$ & $18.7(5.5)$ & 0.007 & $17.6(4.8)$ & $18.6(5.4)$ & $<0.001$ \\
\hline Heart rate, $/ \min ^{6}$ & $86(20)$ & $84(20)$ & $<0.001$ & $86(21)$ & $84(21)$ & $<0.001$ \\
\hline \multicolumn{3}{|l|}{ Testing, $n(\%)$} & $<0.001$ & & & $<0.001$ \\
\hline \\
\hline & & & & & & \\
\hline \multicolumn{7}{|c|}{$\begin{array}{l}\text { Abbreviations: SD: standard deviation. n:number, IQR: interquartile range, GP: general practitioner, min: minute } \\
\text { Vital parameters measured are: } 0_{2} \text { : oxygen saturation, measured in percentage oxygenated haemoglobin. Systolic BP: Systolic blood pressure, measured in millimetres of mercury. }\end{array}$} \\
\hline \multicolumn{7}{|c|}{$\begin{array}{l}\text { Number of measured values per age group. } \\
<70 \text { years:1:n=17009, 2:n=9924, 3:n=10018, } 4: n=9953,5: n=5807,6: n=10371\end{array}$} \\
\hline \multicolumn{5}{|c|}{$\begin{array}{l}\geq 70 \text { years: } 1: n=4118,2: n=3232,3: n=3208,4: n=2890,5: n=2302,6: n=3292 \\
P \text { values are measured by } t \text {-test for scale values and chi-square for categorical values. Mann-Whitney } U \text { test for non-parametric variat }\end{array}$} & & \\
\hline
\end{tabular}

In the derivation cohort, 2,014 (23.1\%) younger patients and 898 (43.2\%) older patients were admitted to the hospital. In the validation cohort, 2,030 (24.1\%) younger patients and 919 (44.4\%) older patients were admitted. Baseline characteristics between patients in the derivation cohort admitted to hospital and those discharged are shown in Table 2.

Table 2. Baseline characteristics of study population, the derivation cohort stratified around hospital admission.

\begin{tabular}{|c|c|c|c|c|c|c|}
\hline \multirow[b]{2}{*}{ Baseline features } & \multicolumn{2}{|c|}{$<70$ years } & \multicolumn{4}{|c|}{$\geq 70$ years } \\
\hline & $\begin{array}{l}\text { Discharged } \\
n=6714\end{array}$ & $\begin{array}{c}\text { Admitted } \\
\mathrm{n}=2014\end{array}$ & $P$ value & $\begin{array}{l}\text { Discharged } \\
n=1181\end{array}$ & $\begin{array}{c}\text { Admitted } \\
n=898\end{array}$ & $P$ value \\
\hline Age, median IQR & $41.9(26.8-55.6)$ & $52.4(40.0-62.0)$ & $<0.001$ & $78.1(73.7-83.4)$ & $78.1(74.2-83.7)$ & 0.280 \\
\hline Male, $n(\%)$ & $3625(54.0)$ & $1137(56.5)$ & 0.052 & $529(44.8)$ & 466 (51.9) & 0.001 \\
\hline Triage category, $n$ (\%) & & & $<0.001$ & & & $<0.001$ \\
\hline$<10$ minutes & 1066 (15.9) & $855(42.5)$ & & $270(22.9)$ & $387(43.1)$ & \\
\hline$<1$ hour & 2609 (38.9) & $958(47.6)$ & & 530 (44.9) & $413(46.0)$ & \\
\hline$<2$ hour & $3007(44.8)$ & $198(9.8)$ & & 374 (31.7) & $98(10.9)$ & \\
\hline$<4$ hours & $32(0.5)$ & $3(0.1)$ & & $7(0.6)$ & $0(0)$ & \\
\hline Arrival mode, $n$ (\%) & & & $<0.001$ & & & $<0.001$ \\
\hline Self-referral & $3648(54.3)$ & $610(30.3)$ & & $303(25.7)$ & $164(18.3)$ & \\
\hline Ambulance/other institution & $782(11.6)$ & $534(26.5)$ & & $287(24.3)$ & 309 (34.4) & \\
\hline Referred by GP/specialist & $2284(34.0)$ & $870(43.2)$ & & $591(50.0)$ & $425(47.3)$ & \\
\hline Type of specialist & & & $<0.001$ & & & $<0.001$ \\
\hline Medicine & $2430(36.2)$ & $1379(68.5)$ & & 605 (51.2) & 646 (71.9) & \\
\hline Surgery & $4284(63.8)$ & $635(31.5)$ & & $576(48.8)$ & $252(28.1)$ & \\
\hline Revisit to the ED, $n(\%)$ & & & $<0.001$ & & & \\
\hline Visit $<30$ days & 595 (8.9) & $327(16.2)$ & & $118(10.0)$ & 129 (14.4) & 0.002 \\
\hline Chief complaint $^{1}$ & & & $<0.001$ & & & $<0.001$ \\
\hline Minor trauma & $3370(50.6)$ & $286(14.3)$ & & $456(39.0)$ & $165(18.4)$ & \\
\hline Major trauma & $103(1.5)$ & $80(4.0)$ & & $11(0.9)$ & $21(2.3)$ & \\
\hline Chest pain & $764(11.5)$ & $216(10.8)$ & & $215(18.4)$ & $87(9.7)$ & \\
\hline Dyspnea & $238(3.6)$ & $188(9.4)$ & & $93(7.9)$ & $128(14.3)$ & \\
\hline Syncope & $141(2.1)$ & $78(3.9)$ & & $64(5.5)$ & $54(6.0)$ & \\
\hline Psychiatric complaints & $127(1.9)$ & $92(4.6)$ & & $13(1.1)$ & $21(2.3)$ & \\
\hline Malaise & $526(7.9)$ & $506(25.3)$ & & $136(11.6)$ & $241(26.9)$ & \\
\hline Abdominal pain & $592(8.9)$ & $343(17.1)$ & & $81(6.9)$ & $102(11.4)$ & \\
\hline Other & $804(12.1)$ & $214(10.7)$ & & $101(8.6)$ & $76(8.5)$ & \\
\hline
\end{tabular}

Vital signs 
Lucke et al. Early prediction of hospital admission for emergency department patients, a comparison between patients younger or older than 70-years

Systolic BP, $\mathrm{mmHg}^{2}$

$138(20)$

$99(98-100)$

$\mathrm{O}_{2}$ saturation, $\%^{3}$ median, IQR

Temperature, ${ }^{\circ} \mathrm{C}^{4}$

$36.9(0.7)$

16.9 (3.9)

Respiratory rate, $/ \mathrm{min}^{5}$

83 (19)

Heart rate, $/ \mathrm{min}^{6}$

Performed test, $\boldsymbol{n}$ (\%)

Phlebotomised blood sample

$\begin{array}{ccc}135(23) & <0.001 & 148(27) \\ 99(97-100) & <0.001 & 98(96-100) \\ 37.2(1.1) & <0.001 & 36.8(0.6) \\ 18.6(5.4) & <0.001 & 17.5(4.3) \\ 91(22) & <0.001 & 82(21) \\ & <0.001 & \end{array}$

$747(63.3)$

$1846(91.7)$

$\begin{array}{cc}142(27) & <0.001 \\ 98(95-99) & <0.001 \\ 37.1(1.2) & <0.001 \\ 19.7(6.1) & <0.001 \\ 86(20.7) & 0.002 \\ & <0.001\end{array}$

$859(95.7)$

a) Values are mean, standard deviation unless noted otherwise

b) Abbreviations: SD: standard deviation. n:number, IQR: interquartile range, GP: general practitioner, min: minute

c) Vital parameters measured are: $\mathrm{O}_{2}$ : oxygen saturation, measured in percentage oxygenated haemoglobin. Systolic BP: Systolic blood pressure, measured in millimetres of mercury. Temperature measured in degrees Celsius. Heart rate and respiratory rate are measured as times per minute.

d) Number of measured values per age group.

$<70$ years: $1: n=8668,2: n=5006,3: n=5000,4: n=4795,5: n=2895,6: n=5178$,

$\geq 70$ years: $1: n=2065,2: n=1589,3: n=1582,4: n=1434,5: n=1154,6: n=1614$

e) $\quad \mathrm{P}$ values are measured by $\mathrm{t}$-test for scale values and chi-square for categorical values. Mann-Whitney $\mathrm{U}$ test for non-parametric variables.

Differences in baseline characteristics between the derivation and validation cohorts, stratified by age, can be found in Supplemental Table 1.

\section{Relationship of patient demographic and clinical factors to hospital admission}

The univariable analyses examining the relationship between patient demographic and clinical characteristics and hospital admission stratified by the two age groups are provided in Supplemental Table 2. The factors associated with hospital admission were the same for both age groups (for example; urgent triage category, phlebotomised blood sample, fever) although the strength of the relationships differed for some factors between age groups. The variables in the final model for the younger patients are age, sex, triage category, arrival mode, chief complaint, ED revisit, type of specialist, phlebotomised blood sample, oxygen saturation, systolic BP, temperature, heart rate and respiratory rate. The variables in the final model for the older patients are triage category, arrival mode, chief complaint, type of specialist, phlebotomised blood sample, oxygen saturation, systolic $\mathrm{BP}$, temperature and respiratory rate.

As shown in the results for the multivariable models by age groups (Table 3), urgent triage category, hospital arrival by ambulance, indication for taking a phlebotomised blood sample, presenting complaint of "malaise", or a non-surgical problem, a systolic blood pressure below $100 \mathrm{mmHg}$, oxygen saturation below $95 \%$, fever or tachypnea >30 breaths/min were associated with greater odds of hospital admission for both age groups. Chest pain, loss of consciousness and dyspnea as a presenting complaint, as well as no measured blood pressure were associated with a significantly decreased odds of being admitted among older patients while in younger patients chest pain decreased the probability of hospital admission. In the sensitivity analyses, similar results were found for the relationship between patient demographic and clinical factors and hospital 
Lucke et al. Early prediction of hospital admission for emergency department patients, a comparison between patients younger or older than 70-years

admission when a single model instead of separate models for the two age groups were used (Supplemental

Table 3) and when a randomly selected training and test cohort were used for these comparisons

(Supplemental Table 4).

Table 3: Final multivariable models of hospitalization of patients at the Emergency Department.

\begin{tabular}{|c|c|c|c|c|c|c|}
\hline \multirow{3}{*}{$\begin{array}{l}\text { Predictor } \\
\text { Age/10 }\end{array}$} & \multicolumn{3}{|c|}{$<70$ years } & \multicolumn{3}{|c|}{$\geq 70$ years } \\
\hline & \multirow{2}{*}{$\begin{array}{c}\text { OR } \\
1.25\end{array}$} & \multicolumn{2}{|c|}{$95 \% \mathrm{Cl}$} & \multirow[t]{2}{*}{ OR } & \multicolumn{2}{|c|}{$95 \% \mathrm{Cl}$} \\
\hline & & 1.19 & 1.30 & & & \\
\hline \multicolumn{7}{|l|}{ Sex } \\
\hline Male & 1.25 & 1.11 & 1.42 & & & \\
\hline Female & ref & ref & ref & & & \\
\hline \multicolumn{7}{|l|}{ Triage category } \\
\hline$>1$ hour & ref & ref & ref & ref & ref & ref \\
\hline$<1$ hour & 2.22 & 1.85 & 2.67 & 1.72 & 1.27 & 2.33 \\
\hline$<10 \min$ & 3.64 & 2.93 & 4.52 & 3.15 & 2.19 & 4.53 \\
\hline \multicolumn{7}{|l|}{ Arrival mode } \\
\hline Self- referral & ref & ref & ref & ref & ref & ref \\
\hline Referred & 1.21 & 1.05 & 1.40 & 1.09 & 0.82 & 1.44 \\
\hline Ambulance & 1.94 & 1.63 & 2.32 & 1.40 & 1.03 & 1.90 \\
\hline \multicolumn{7}{|l|}{ Chief Complaint } \\
\hline Minor trauma & ref & ref & ref & ref & ref & ref \\
\hline Major trauma & 1.31 & 0.89 & 1.94 & 0.90 & 0.39 & 2.08 \\
\hline Chest pain & 0.28 & 0.21 & 0.36 & 0.19 & 0.13 & 0.29 \\
\hline Dyspnea & 0.79 & 0.58 & 1.07 & 0.44 & 0.28 & 0.68 \\
\hline Syncope & 0.74 & 0.51 & 1.06 & 0.52 & 0.32 & 0.83 \\
\hline Psychiatric & 1.48 & 1.03 & 2.13 & 1.29 & 0.59 & 2.84 \\
\hline Malaise & 1.31 & 1.03 & 1.66 & 1.27 & 0.90 & 1.78 \\
\hline Abdominal pain & 1.34 & 1.07 & 1.68 & 1.11 & 0.74 & 1.66 \\
\hline Other & 1.13 & 0.89 & 1.43 & 1.23 & 0.80 & 1.88 \\
\hline \multicolumn{7}{|l|}{ Type of specialist } \\
\hline Medicine & 1.17 & 0.99 & 1.37 & & & \\
\hline Surgery & ref & ref & ref & & & \\
\hline Revisit to the ED & 1.57 & 1.32 & 1.88 & 1.94 & 1.41 & 2.67 \\
\hline $\begin{array}{l}\text { Phlebomotised } \\
\text { blood sample } \\
\text { Oxygen saturation }\end{array}$ & 4.79 & 3.83 & 5.99 & 7.46 & 4.94 & 11.28 \\
\hline$\leq 90 \%$ & 1.80 & 0.93 & 3.48 & 4.26 & 1.77 & 10.25 \\
\hline $91-94 \%$ & 1.78 & 1.26 & 2.51 & 1.62 & 1.04 & 2.52 \\
\hline$\geq 95 \%$ & ref & ref & ref & ref & ref & ref \\
\hline Missing & 1.11 & 0.81 & 1.52 & 1.14 & 0.67 & 1.92 \\
\hline \multicolumn{7}{|l|}{ Systolic BP } \\
\hline$\leq 100$ & 1.96 & 1.33 & 2.88 & 1.67 & 0.91 & 3.06 \\
\hline 101-199 & ref & ref & ref & ref & ref & ref \\
\hline$>200$ & 1.32 & 0.70 & 2.47 & 0.74 & 0.41 & 1.32 \\
\hline Missing & 0.57 & 0.40 & 0.82 & 0.52 & 0.30 & 0.89 \\
\hline \multicolumn{7}{|l|}{ Temperature } \\
\hline$\leq 35.0$ & 1.86 & 0.89 & 3.87 & 0.96 & 0.36 & 2.56 \\
\hline $35.1-38.4$ & ref & ref & ref & ref & ref & ref \\
\hline$>38.5$ & 3.34 & 2.41 & 4.61 & 3.43 & 1.82 & 6.47 \\
\hline Missing & 0.85 & 0.70 & 1.02 & 0.93 & 0.69 & 1.25 \\
\hline
\end{tabular}


Lucke et al. Early prediction of hospital admission for emergency department patients, a comparison between patients younger or older than 70-years

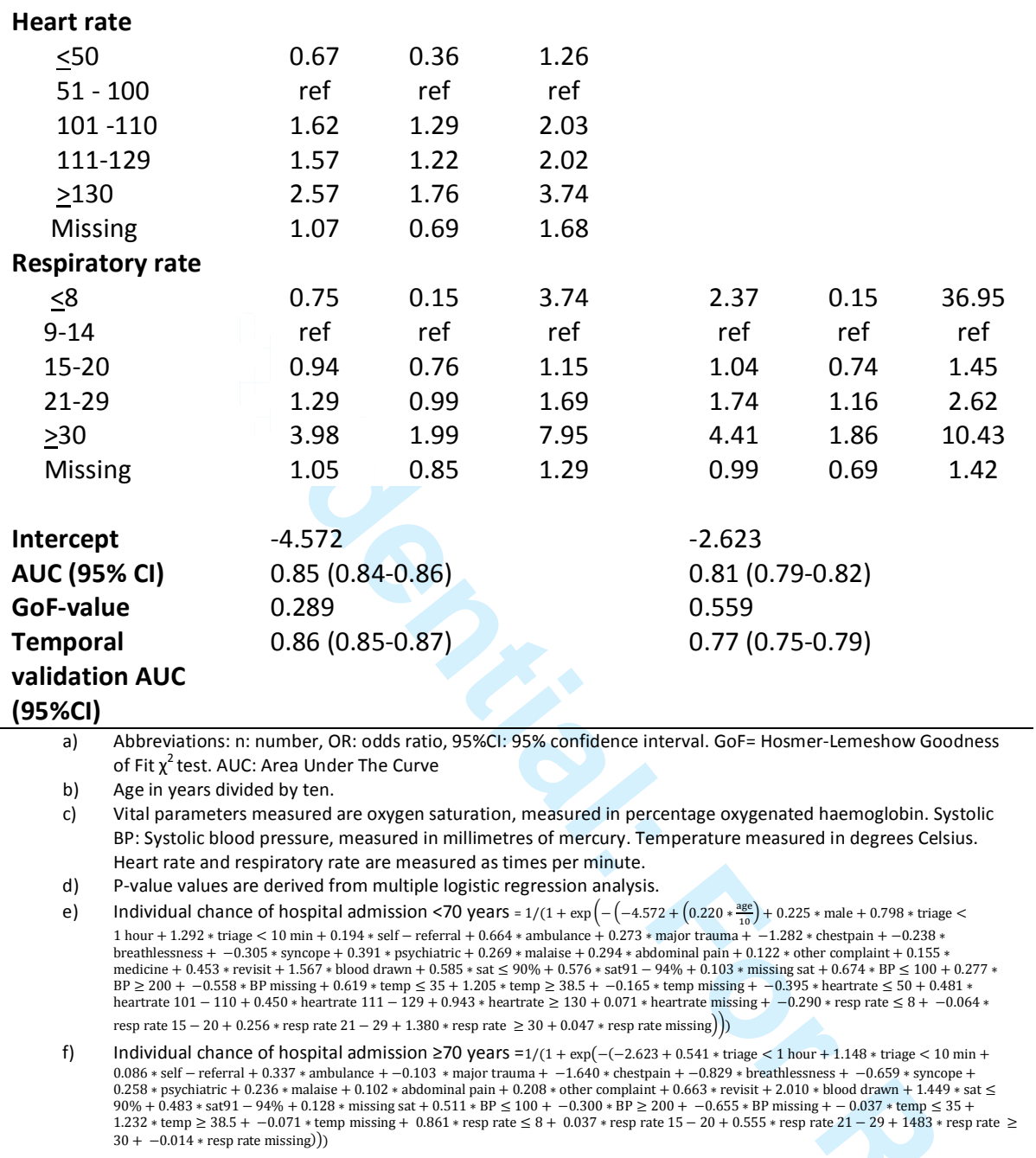

The AUC of the prediction model for the derivation cohort for hospital admission among patients $<70$ years-old was $0.85(95 \% \mathrm{Cl} 0.84-0.86)$, which was higher than the AUC of the prediction model for $\geq 70$ years-old $(0.81$

(95\% $\mathrm{Cl} 0.79-0.82)$. In the temporal validation cohort, the AUC for younger patients was $0.86(95 \% \mathrm{Cl} 0.85-$

0.87), which also was higher than the model for older patients, which was 0.77 ( $95 \% \mathrm{Cl} 0.75-0.79)$.

The calibration plots in Figure 2 show the observed hospital admission rate in relation to the predicted chance of hospital admission in the validation group. The Hosmer-Lemeshow Goodness of Fit-test in both groups was $p>0.05$, suggesting that predicted probabilities are in line with the observed and that the model fit the data well. In a sensitivity analysis using different cut-off points for vital signs in younger and older patients, there were no differences in the performance of either model.

As shown in Figure 3, there were more younger adult patients with a lower predicted chance of hospital admission in the validation cohort than for the older adult group. The predicted chance of hospital admission was also more equally distributed among the older patients. Table 4 depicts the test performance parameters 
Lucke et al. Early prediction of hospital admission for emergency department patients, a comparison between patients younger or older than 70 -years

of the models in predicting hospital admission by age group. Specificity, PPV and LR+ were higher in older patients. The prediction model shows superior predictive applicability than for example triage category alone.

2

3

4

5

6

7

8

9

10

11

12

13

14

15

16

17

18

19

20

21

22

23

24

25

26

27

28

29

30

31

32

33

34

35

36

37

38

39

40

41

42

43

44

45

46

47

48

49

50

51

52

53

54

55

56

57

58

59

60 
Lucke et al. Early prediction of hospital admission for emergency department patients, a comparison between patients younger or older than 70-years.

Table 4: Predictive applicability of prediction model in validation cohort

\begin{tabular}{|c|c|c|c|c|c|c|}
\hline & Sens $(95 \% \mathrm{Cl})$ & Spec $(95 \% \mathrm{Cl})$ & $\operatorname{PPV}(95 \% \mathrm{Cl})$ & $\mathrm{NPV}(95 \% \mathrm{Cl})$ & LR+(95\% Cl) & LR-(95\% CI) \\
\hline \multicolumn{7}{|c|}{$\begin{array}{l}10 \% \text { of population with } \\
\text { highest risk of hospital } \\
\text { admission }\end{array}$} \\
\hline$<70$ years & $0.30(0.28-0.32)$ & $0.96(0.96-0.97)$ & $0.71(0.68-0.74)$ & $0.81(0.80-0.82)$ & $7.85(6.81-9.04)$ & $0.73(0.71-0.75)$ \\
\hline$\geq 70$ years & $0.19(0.17-0.22)$ & $0.98(0.96-0.98)$ & $0.87(0.81-0.91)$ & $0.60(0.58-0.62)$ & $8.23(5.54-12.2)$ & $0.82(0.80-0.85)$ \\
\hline \multicolumn{7}{|c|}{ Triage category - $<10 \mathrm{~min}$} \\
\hline$<70$ years & $0.42(0.40-0.44)$ & $0.84(0.83-0.85)$ & $0.45(0.43-0.47)$ & $0.82(0.81-0.83)$ & $2.58(2.39-2.78)$ & $0.69(0.68-0.72)$ \\
\hline$\geq 70$ years & $0.46(0.42-0.49)$ & $0.77(0.75-0.80)$ & $0.61(0.58-0.65)$ & $0.64(0.61-0.67)$ & $1.99(1.76-2.27)$ & $0.70(0.66-0.75)$ \\
\hline
\end{tabular}

likelihood ratio, AUC: area under the curve 
Lucke et al. Early prediction of hospital admission for emergency department patients, a comparison between patients younger or older than 70-years.

\section{DISCUSSION}

In this investigation, we found that routinely collected demographic and clinical patient data at ED triage can be used to predict hospital admission among ED patients. However, although the predictors of hospital admission are the same regardless of age groups, the strength of the relationships between patient demographic and clinical factors and hospital admission as well as the performance of the predictive models differ by age groups ( $<70$ year-old vs. $\geq 70$ years-old). Overall predictive performance of the model was better for younger patients, although positive predictive value was higher among older patients.

Our findings are in concordance with prior studies[7 914 20] [10]. Most of these variables, like triage category[13], chief complaint and abnormal vital signs[9], reflect illness severity at ED presentation. Sun et al.[14] derived a prediction model for hospital admission in over 300.00 ED patients in Singapore. It was validated using split-validation and the model used age, race, arrival mode, triage category, preceding hospital admission or ED visit and chronic conditions as predictors. The AUC of this model was 0.85 , which is comparable to our findings. Cameron et al. created a similar prediction model in over 300.000 adult ED patients in Scotland. This prediction model used age, early warning score, triage category, referral and arrival mode and preceding hospital admission within one year and found an AUC of 0.88. A model by Meisel et al. in the United States to predict hospital admission in the pre-hospital phase used age and chief complaint as predictors and found an AUC of $0.80[20]$. For all these studies, the investigators observed that age was an important factor in predicting hospital admission, however they did not compare the predictive properties of disease severity between the younger and older patients. A prediction model for hospitalization for ED patients in 4,873 patients $\geq 75$ years-old by LaMantia et al[21] , included injury severity, heart rate, diastolic blood pressure and patient chief complaint as predictors had an AUC of $0.73(95 \% \mathrm{Cl} 0.69-0.76)$, with a sensitivity of $33 \%$, specificity $88 \%$ and LR of 2.75 . Our model performed better, possibly due to inclusion of more demographic and clinical characteristics. Also sample size, differences in care system and selection of patients could have influenced the performance of the models. Physiology, polypharmacy and multi-morbidity affects the measured vital signs of older patients, and some studies indicate that when relying solely on vital signs a proportion of severely ill older patients will be missed [12]. To address this concern, we assessed 
Lucke et al. Early prediction of hospital admission for emergency department patients, a comparison between patients younger or older than 70-years

whether the predictors of hospital admission are different for older as compared to younger adult ED patients. In our model for older patients, age was not a predictor. One explanation for this observation may be that by limiting the age range to those 70 years-old and older to assess the predictive value of age there was limited contrast in this population and hence a lack of power to detect differences by age. As an alternative explanation, among older patients disease severity and geriatric factors (eg. pre-existing functional or cognitive impairment) are more important than calendar age. As shown in Table 2 there is no difference between median age for patients hospitalized or discharged in the older age group. For these reasons models that combine predictors of disease severity and geriatric factors may perform even better than ours, but such models do not exist yet.

In contrast to the prediction rule derived by Meisel et al. 'chest pain' as chief complaint was associated with a lower probability of hospital admission in our models for both older and younger patients. This observation could be explained by the care system in the region where the study was performed that patients with STelevation myocardial infarction bypass this ED and go to the heart-catheterisation laboratory immediately[22]. Older patients with dyspnea and syncope also had a decreased chance of hospital admission, which we explain by the fact that those patients with severe dyspnea or who have not regained consciousness after syncope are triaged 'red' and were excluded from the study.

Although it was one of the important predictors of hospital admission in our models, there were missing values for vital signs in our study database. We believe that these values are missing because the triage nurse probably deemed vital signs registration unnecessary if the patient was not perceived ill. Using missing measurements of vital signs, such as the absence of measured blood pressure, as valuable information in this study, seemed to be a marker of being less ill (Table 3). Using the combination of predictors in this study into a prediction model successfully identified the $10 \%$ of the ED patient population with the highest risk of hospital admission, for both younger and older patients.

The prediction model for older patients had a lower AUC but higher PPV for this population. When predicting chance of hospital admission, one would want a high positive predictive value. When designing an intervention based on such a prediction model, the patients with the highest risk should be targeted to prevent unnecessary and costly admissions. A low number of false-positives is therefore desirable. 
Lucke et al. Early prediction of hospital admission for emergency department patients, a comparison between patients younger or older than 70-years

Using the prediction model created in this study identifies the $10 \%$ of the ED patient population with the highest probability of hospital admission with a PPV of $71 \%$ in the young and $81 \%$ in the old.

The PPV for hospital admission was higher in older than in younger patients, likely due to the higher a priori chance of hospital admission for older patients (derivation cohort: $23.1 \%$ admission rate in younger patients vs. $43.2 \%$ for older patients, validation cohort $24.1 \%$ admission rate in younger patients, $44.4 \%$ in older patients). In addition, the LR+ was slightly better for older patients, which increases its clinical utility. Thus, this tool could trigger early awareness of the high chance of hospital admission, which could affect the clinical decision-making, preparation for admission, enhancement of ED work flow and shortened length of ED stay. The overall discriminative performance of the model and odds ratios of the individual predictors were significantly higher for younger patients. This observation could be explained by three different mechanisms. First, the relationship between vital signs and disease severity is likely to be different between younger and older patients. It is well known that with aging the physiology of the body changes, with less homeostatic, respiratory and cardiovascular reserve. In combination with polypharmacy (eg. beta-blockers), severely ill older patients show less prominent vital sign abnormalities. For example, in this study heart rate was an independent predictor for younger but not older patients. This finding was also shown in two recent studies in which normal vital signs proved to be less specific for the absence of severe illness for older adults[23] [24]. This phenomenon is not captured using standard MEWS-cut off points and could explain a part of the difference in discriminative power between models observed in this study. Second, older patients with multiple comorbidities are often in a delicate equilibrium in which they can still function with relative independence and health. However, relative minor trauma or disease can disturb this equilibrium and result in severe illness and need for hospitalization[25]. The absence of comorbidities in our model and other or currently existing models, could also explain the difference in the discriminative performance between the models for younger and older patients [10 11]. Finally, older patients are sometimes hospitalized for their increased vulnerability rather than disease severity. For example, a patient with a small social network and low functional capabilities with the same minor trauma as a younger person, would more easily be hospitalized. It has recently been shown that tools that exclusively use frailty to predict adverse outcomes in older patients, lack specificity and predictive capability[6]. The fact that overall discriminative performance of our model for the older group was lower could be explained by the lack of information about conditions more prevalent among older patients such as impaired cognitive function 
Lucke et al. Early prediction of hospital admission for emergency department patients, a comparison between patients younger or older than 70-years

and functional status.

We therefore hypothesize that the combination of two dimensions: 'disease severity' and 'geriatric

phenotypes' such as multi-morbidity and social, cognitive and physical function of the acutely presenting older patient, will result in an optimal model for prediction of adverse events and hospitalization.

Strengths of this study are the large number of patients and events. These features enable better estimates of test performance parameters of the models. The clear and clinically relevant endpoint also is one of the strengths, as it is without bias whether a patient was admitted or not. The present study had several limitations. First, this was a retrospective study which limits the ability to examine possible predictors which might have been obtained prospectively. There is also risk for information bias, although this was minimized by automatically harvesting data from the electronic patient files. Possible variables were selected based upon earlier research, clinical judgement and availability in the ED records. The second threat was missing measurements of vital signs, for which we conceived a solution. The fact that a parameter was not measured in a specific patient was considered to contain information with respect to the indication to perform such a measurement and as such analysed alongside measured values rather than imputed. Third, there were no data available on geriatric phenotypes such as multi-morbidity and social, cognitive and physical function, also the comorbidities in young patients are lacking. Whilst these factors could have an important impact on hospitalization, it was possible to create a robust model with high specificity. Fourth, we used temporal validation to validate the model. Temporal factors could affect who was admitted, for example time of year and changes in admission over time. However, as a sensitivity analysis we performed the same study with a randomly selected split-cohort and found similar results.

Finally, the admission rate in the current single centre study may be different in other care systems which influences its clinical applicability and PPVs of prediction models. While the prediction models has been created according to the recommendations by Stiell. et al[26] and has been internally validated using temporal data, it was not prospectively validated, evaluated in another patient population, implemented and disseminated or analysed for cost-effectiveness because it is still in the early stages of development.

In summary, the composition of prediction models for hospital admission are similar for ED patients younger 
2

3

4

5

6

7

8

9

10

11

12

13

14

15

16

17

18

19

20

21

22

23

24

25

26

27

28

29

30

31

32

33

34

35

36

37

38

39

40

41

42

43

44

45

46

47

48

49

50

51

52

53

54

55

56

57

58

59

60

Lucke et al. Early prediction of hospital admission for emergency department patients, a comparison between patients younger or older than 70-years

and older than 70 years-old, although the AUC is higher in the model for younger patients and the model for older patients showed a higher PPV and LR+. This retrospective study could help identify determinants of admission in older ED patients. Further research should investigate the combination of disease severity with frailty to improve prediction of hospital admission. We are currently performing a multicentre, prospective follow up study (www.apop.eu)[27] in which we will derive, validate and implement a prediction model according to internationally acknowledged recommendations[26] to optimize care for this vulnerable patient group. 
Lucke et al. Early prediction of hospital admission for emergency department patients, a comparison between patients younger or older than 70-years

\section{AKNOWLEDGEMENT}

The authors would like to thank Mary Ann Etty (Department of Information Technology, Leiden University Medical Center, Leiden, The Netherlands) for her help in extracting the data from the medical records. Anton J.M. De Craen deceased on January $17^{\text {th }} 2016$.

\section{FUNDING}

The Institute for Evidence-Based Medicine in Old Age (IEMO) is funded by the Dutch Ministry of Health and Welfare and supported by ZonMW (project number 62700.3002). The funding organization had no role in the design or conducts of the study, neither in the data collection and analyses or the interpretation of the data.

\section{DISCLOSURES}

The authors declare no conflict of interest.

\section{AUTHOR CONTRIBUTION STATEMENT}

SPM, GJB, CH, AJF and BG designed the study. SPM and GJB obtained funding. JAL and JDG collected the data from the electronic patient files and JAL checked them for validity. AJMC provided statistical advice. JAL and FC performed the statistical analysis and drafted the paper. BG and SPM advised during the drafting process. All authors contributed to its revision and gave approval of the final version of the article.

\section{COMPLIANCE WITH ETHICAL STANDARDS}

The Medical Ethics Committee waived the need for informed consent as data were collected as part of past clinical care and handled anonymously. 
Lucke et al. Early prediction of hospital admission for emergency department patients, a comparison between patients younger or older than 70-years

\section{REFERENCES}

1. Aminzadeh F, Dalziel WB. Older adults in the emergency department: a systematic review of patterns of use, adverse outcomes, and effectiveness of interventions. Annals of emergency medicine 2002;39(3):238-47

2. Gruneir A, Silver MJ, Rochon PA. Emergency department use by older adults: a literature review on trends, appropriateness, and consequences of unmet health care needs. Medical care research and review : MCRR 2011;68(2):131-55 doi: 10.1177/1077558710379422[published Online First: Epub Date]|.

3. Latham LP, Ackroyd-Stolarz S. Emergency department utilization by older adults: a descriptive study. Canadian geriatrics journal : CGJ 2014;17(4):118-25 doi: 10.5770/cgj.17.108[published Online First: Epub Date]|.

4. Kennelly SP, Drumm B, Coughlan T, et al. Characteristics and outcomes of older persons attending the emergency department: a retrospective cohort study. QJM : monthly journal of the Association of Physicians 2014;107(12):977-87 doi: 10.1093/qjmed/hcu111[published Online First: Epub Date]|.

5. Ackroyd-Stolarz S, Read Guernsey J, Mackinnon NJ, et al. The association between a prolonged stay in the emergency department and adverse events in older patients admitted to hospital: a retrospective cohort study. BMJ quality \& safety 2011;20(7):564-9 doi: 10.1136/bmjqs.2009.034926[published Online First: Epub Date]|.

6. Carpenter CR, Shelton E, Fowler S, et al. Risk Factors and Screening Instruments to Predict Adverse Outcomes for Undifferentiated Older Emergency Department Patients: A Systematic Review and Meta-analysis. Academic emergency medicine : official journal of the Society for Academic Emergency Medicine 2015;22(1):1-21 doi: 10.1111/acem.12569[published Online First: Epub Date]|.

7. Cameron A, Rodgers K, Ireland A, et al. A simple tool to predict admission at the time of triage. Emergency medicine journal : EMJ 2015;32(3):174-9 doi: 10.1136/emermed-2013203200[published Online First: Epub Date]|.

8. Subbe $C P$, Kruger $M$, Rutherford $P$, et al. Validation of a modified Early Warning Score in medical admissions. QJM : monthly journal of the Association of Physicians 2001;94(10):521-6

9. Burch VC, Tarr G, Morroni C. Modified early warning score predicts the need for hospital admission and inhospital mortality. Emergency medicine journal : EMJ 2008;25(10):674-8 doi: 10.1136/emj.2007.057661[published Online First: Epub Date]|.

10. Dundar ZD, Ergin M, Karamercan MA, et al. Modified Early Warning Score and VitalPac Early Warning Score in geriatric patients admitted to emergency department. European journal of emergency medicine : official journal of the European Society for Emergency Medicine 2015 doi: 10.1097/MEJ.0000000000000274[published Online First: Epub Date]|.

11. Cei M, Bartolomei C, Mumoli N. In-hospital mortality and morbidity of elderly medical patients can be predicted at admission by the Modified Early Warning Score: a prospective study. International journal of clinical practice 2009;63(4):591-5 doi: 10.1111/j.17421241.2008.01986.x[published Online First: Epub Date]|.

12. Lamantia MA, Stewart PW, Platts-Mills TF, et al. Predictive value of initial triage vital signs for critically ill older adults. The western journal of emergency medicine 2013;14(5):453-60 doi: 10.5811/westjem.2013.5.13411[published Online First: Epub Date]|.

13. van der Wulp I, van Baar ME, Schrijvers AJ. Reliability and validity of the Manchester Triage System in a general emergency department patient population in the Netherlands: results of a simulation study. Emergency medicine journal : EMJ 2008;25(7):431-4 doi: 10.1136/emj.2007.055228[published Online First: Epub Date]|.

14. Sun $\mathrm{Y}$, Heng BH, Tay SY, et al. Predicting hospital admissions at emergency department triage using routine administrative data. Academic emergency medicine : official journal of the 
Lucke et al. Early prediction of hospital admission for emergency department patients, a comparison between patients younger or older than 70-years

Society for Academic Emergency Medicine 2011;18(8):844-50 doi: 10.1111/j.15532712.2011.01125.x[published Online First: Epub Date]|.

15. Dexheimer JW, Leegon J, Aronsky D. Predicting hospital admission at triage in an emergency department. AMIA Annual Symposium proceedings / AMIA Symposium AMIA Symposium 2007:937

16. Barfod C, Lauritzen MM, Danker JK, et al. Abnormal vital signs are strong predictors for intensive care unit admission and in-hospital mortality in adults triaged in the emergency department - a prospective cohort study. Scandinavian journal of trauma, resuscitation and emergency medicine 2012;20:28 doi: 10.1186/1757-7241-20-28[published Online First: Epub Date]|.

17. De Rooij SE, Emmelot-Vonk MH, A. E. Praktijkgids 'Kwetsbare Ouderen'. Den Haag, 2009.

18. Harrell FE, Jr., Lee KL, Mark DB. Multivariable prognostic models: issues in developing models, evaluating assumptions and adequacy, and measuring and reducing errors. Statistics in medicine 1996;15(4):361-87 doi: 10.1002/(SICI)1097-0258(19960229)15:4<361::AIDSIM168>3.0.CO;2-4[published Online First: Epub Date]|.

19. Paul P, Pennell ML, Lemeshow S. Standardizing the power of the Hosmer-Lemeshow goodness of fit test in large data sets. Statistics in medicine 2013;32(1):67-80 doi: 10.1002/sim.5525[published Online First: Epub Date]|.

20. Meisel ZF, Pollack CV, Mechem CC, et al. Derivation and internal validation of a rule to predict hospital admission in prehospital patients. Prehospital emergency care : official journal of the National Association of EMS Physicians and the National Association of State EMS Directors 2008;12(3):314-9 doi: 10.1080/10903120802096647[published Online First: Epub Date]|.

21. LaMantia MA, Platts-Mills TF, Biese $K$, et al. Predicting hospital admission and returns to the emergency department for elderly patients. Academic emergency medicine : official journal of the Society for Academic Emergency Medicine 2010;17(3):252-9 doi: 10.1111/j.15532712.2009.00675.x[published Online First: Epub Date]|.

22. Liem SS, van der Hoeven BL, Oemrawsingh PV, et al. MISSION!: optimization of acute and chronic care for patients with acute myocardial infarction. Am Heart J 2007;153(1):14 e1-11 doi: 10.1016/j.ahj.2006.10.002[published Online First: Epub Date]|.

23. Brown JB, Gestring ML, Forsythe RM, et al. Systolic blood pressure criteria in the National Trauma Triage Protocol for geriatric trauma: 110 is the new 90. The journal of trauma and acute care surgery 2015;78(2):352-9 doi: 10.1097/TA.0000000000000523[published Online First: Epub Date]|.

24. Heffernan DS, Thakkar RK, Monaghan SF, et al. Normal presenting vital signs are unreliable in geriatric blunt trauma victims. The Journal of trauma 2010;69(4):813-20 doi: 10.1097/TA.0b013e3181f41af8[published Online First: Epub Date]|.

25. Olde Rikkert M.G.M RJFM, Jurgen A.H.R. Claassen. Waarschuwingssignalen voor acute verergering van chronische ziekten. Ned Tijdschr Geneeskd 2015;159:A8150

26. Stiell IG, Wells GA. Methodologic standards for the development of clinical decision rules in emergency medicine. Annals of emergency medicine 1999;33(4):437-47

27. De Gelder J, Lucke J, De Groot B, et al. Predicting adverse health outcomes in older emergency department patients: the APOP study. Netherlands Journal of Medicine 2016;74(8):342-52 
2

3

4

5

6

7

8

9

10

11

12

13

14

15

16

17

18

19

20

21

22

23

24

25

26

27

28

29

30

31

32

33

34

35

36

37

38

39

40

41

42

43

44

45

46

47

48

49

50

51

52

53

54

55

56

57

58

59

60

Lucke et al. Early prediction of hospital admission for emergency department patients, a comparison between patients younger or older than 70 -years.

\section{LEGENDS OF FIGURES}

Figure 1: Flowchart of participant selection.

ED: Emergency department. CPR: cardiopulmonary resuscitation. Red triage: most urgent triage category, needing immediate care, often in trauma room. ED use for logistical reasons means a pre-planned reevaluation, laboratory check or patient who had left without being seen. Individual visits were included, there can be multiple visits of one patient in this study.

Figure 2: Calibration plot of expected and observed chance of admission for patients aged $<70$ and $\geq 70$ years - validation cohort.

Patients are divided into ten equal groups to compare expected and observed chance of admission per group. Ideally the dots would be aligned across the grey striped line. • Indicates decile of patient group.

Figure 3: Distribution of chance of admission predicted by our model for patients aged $<70$ and $\geq 70$ years validation cohort.

The $x$-axes is a scale of individually predicted chance of hospital admission, ranging from $0-100 \%$. On the $y$-axes is the percentage of patients in the study with that individual risk. 
Lucke et al. Early prediction of hospital admission for emergency department patients, a comparison between patients younger or older than 70-years. 
1

2

3

4

5

6

7

8

9

10

11

12

13

14

15

16

17

18

19

20

21

22

23

24

25

26

27

28

29

30

31

32

33

34

35

36

37

38

39

40

41

42

43

44

45

46

47

48

49

50

51

52

53

54

55

56

57

58

59

60

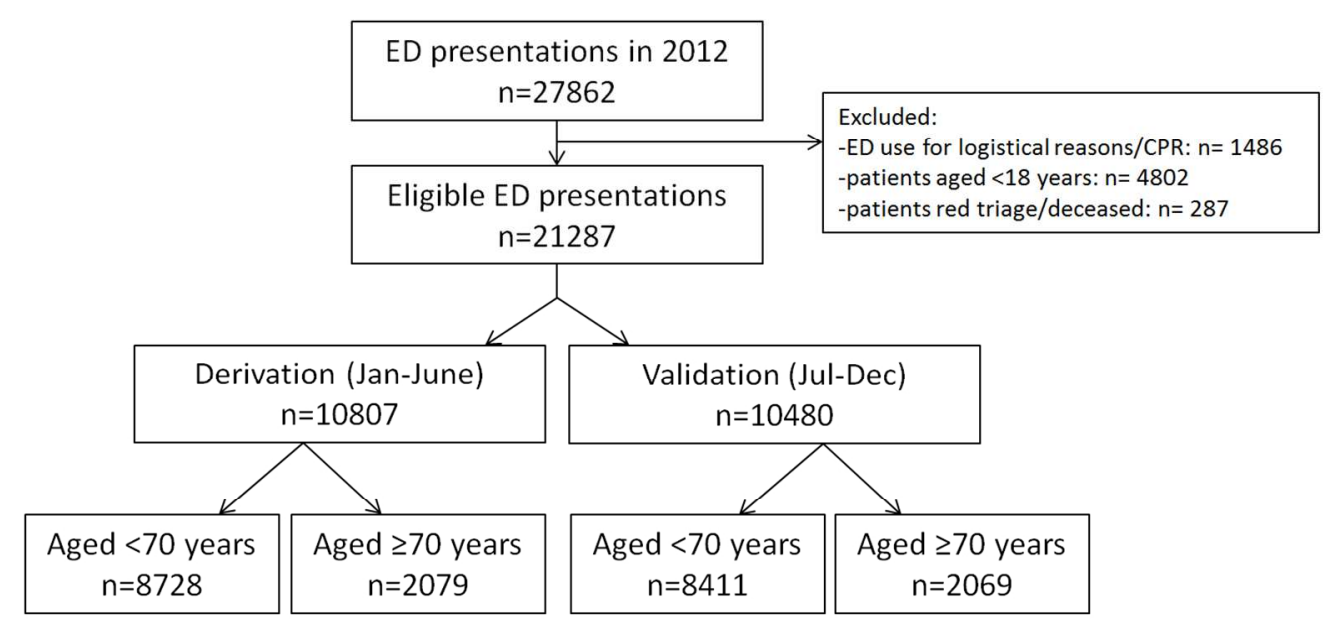

ED: Emergency department. CPR: cardiopulmonary resuscitation. Red triage: most urgent triage category, needing immediate care, often in trauma room. ED use for logistical reasons means a pre-planned reevaluation, laboratory check or patient who had left without being seen. Individual visits were included, there can be multiple visits of one patient in this study.

$388 \times 179 \mathrm{~mm}(96 \times 96 \mathrm{DPI})$ 
Patients aged $<70$ years

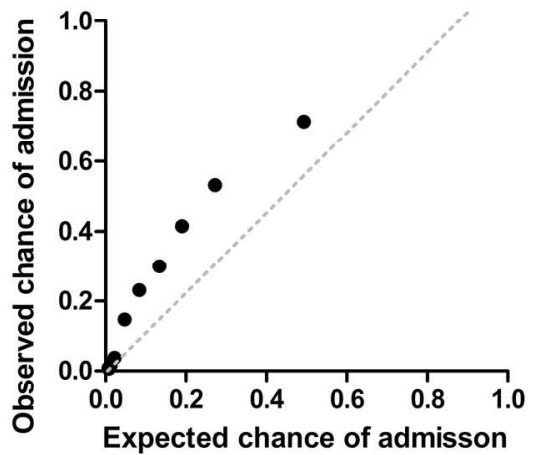

Patients aged $>70$ years

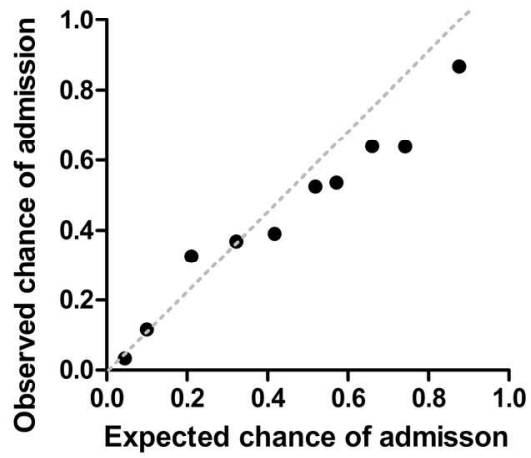

Figure 2: Calibration plot of expected and observed chance of admission for patients aged $<70$ and $\geq 70$ years - validation cohort.

Patients are divided into ten equal groups to compare expected and observed chance of admission per group. Ideally the dots would be aligned across the grey striped line. • Indicates decile of patient group.

$84 \times 39 \mathrm{~mm}(600 \times 600$ DPI $)$ 

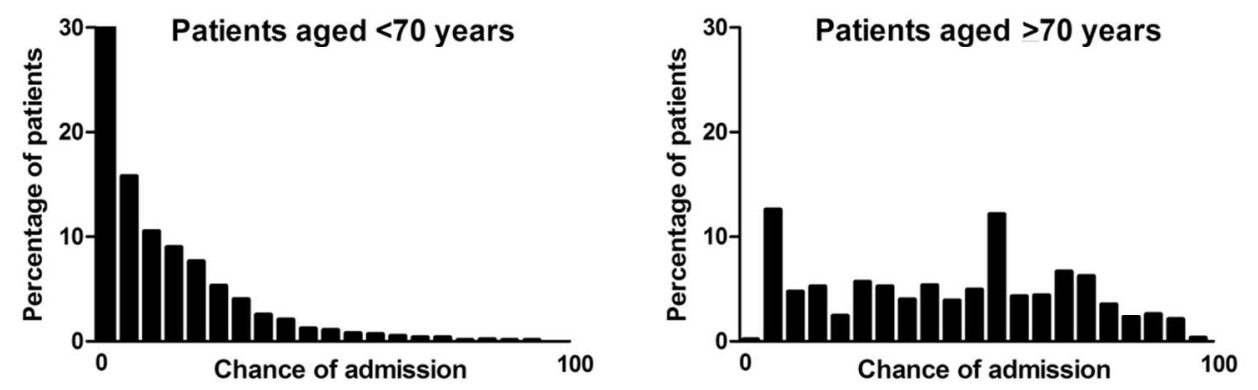

Figure 3: Distribution of chance of admission predicted by our model for patients aged $<70$ and $\geq 70$ years validation cohort.

The $x$-axes is a scale of individually predicted chance of hospital admission, ranging from $0-100 \%$. On the $y-$ axes is the percentage of patients in the study with that individual risk.

$$
99 \times 41 \mathrm{~mm}(300 \times 300 \mathrm{DPI})
$$


Appendix 1: Description of collection and categorizing of variables.

\title{
DATA COLLECTION
}

\author{
Age and sex \\ Age and sex of the patient are checked with the identity card of the patient.

\section{Triage category and chief complaint}

All patients are triaged upon ED arrival by an ED-nurse according to the Manchester Triage System (MTS)[1]. The MTS consists of 52 presenting complaints to determine the patients acuity. Per presenting complaint, key questions further specify the patients acuity. Finally, questions and measurements using the $A B C D E$ assessment are used to determine the definitive triage category. The most urgent category (red), needing immediate care, were excluded. In order of urgency the next categories are: orange (care $<10$ minutes), yellow (care $<1$ hour), green (care $<2$ hours), blue (care $<4$ hours). For example, the presenting complaint fever would become yellow, but if the patient has an oxygen saturation less than $90 \%$ it would become orange or even red. The chief complaint was assessed using one of 52 categories available in the MTS and grouped into nine categories for analysis (appendix 2).

\section{Mode of arrival}

Patients were divided into three groups of arrival: self-referral, referred by a physician (general practitioner or medical specialist), or ambulance. When a patient was referred by a doctor, but travelled to the ED by ambulance this was categorized as 'Ambulance'. Transfers to our ED from other hospitals were also in this category.

\section{Type of specialist}

Type of specialist that the patient was assigned to was categorized into surgical (for example: surgery, orthopedics, urology) or medical (for example: internal medicine, neurology, cardiology, pulmonology).

\section{Revisit within 30 days}

From the electronic patient files data was derived as to whether the patient visited our ED within 30 days prior to the included visit. The variable 'revisit within 30 days' indicates that the index visit is their second visit within 30 days prior to the index visit.

\section{Drawing of blood}

The nurse caring for the patient draws blood according to protocol and the chief complaint, in consultation 
with the responsible physician. The decision to draw blood is made as soon as possible after the arrival of the patient, often within minutes. If no laboratory results were noted in the electronic patient file from the day of the ED visit, this was categorized as 'no phlebotomised blood sample'.

\section{Vital signs}

The nurse caring for the patient measures vital signs according to protocol and chief complaint, in consultation with the responsible physician. Oxygen saturation, blood pressure, respiratory rate and heart rate were measured using a medical monitor (IntelliVue $\mathrm{MP50}^{\circledR}$, Amsterdam, The Netherlands) and manually registered into the patient file. Temperature was measured using a tympanic thermometer (Genius $2^{\circledR}$, Mansfield, U.S.) and manually registered. The categories for vital parameters were selected according to the Modified Early Warning Score (MEWS)[2], with categories containing less than $1 \%$ of patients being merged. Missing vital signs were not imputed, but analyzed alongside registered data because a valid measurement also indicates necessity. Besides the indication for a measurement, we assessed whether the vital sign was considered too high or too low according to MEWS.

\section{References:}

1. Azeredo TR, Guedes HM, Rebelo de Almeida RA, et al. Efficacy of the Manchester Triage System: a systematic review. International emergency nursing 2015;23(2):47-52 doi: 10.1016/j.ienj.2014.06.001[published Online First: Epub Date]|.

2. Subbe $C P$, Kruger $M$, Rutherford $P$, et al. Validation of a modified Early Warning Score in medical admissions. QJM : monthly journal of the Association of Physicians 2001;94(10):521-6 
Appendix 2: Categories of presenting complaints

\section{CATEGORIES OF PRESENTING COMPLAINTS}

9 groups of presenting complaints.

1. Minor trauma injuries

2. Major trauma injuries

3. Chest pain

4. Dyspnea

5. Syncope

6. Mental Health Problems

7. Malaise

8. Abdominal Pain

9. Others

52 possible flowcharts of Manchester Triage System re-categorized in 9 groups of presenting complaints:

1. Abdominal pain in adults

2. Abdominal pain in children

3. Abscesses and local infections

4. Allergy

5. Apparently drunk

6. Assault

7. Asthma

8. Back pain

9. Behaving strangely

10. Bites and stings

11. Burns and scalds

12. Chest pain

13. Collapsed adult

14. Crying baby
Abdominal pain (8)

Irrelevant

Minor trauma injuries (1)

Others (9)

Others (9)

Minor Trauma Injuries (1)

Dyspnea (4)

Others (9)

Mental Health Problems (6)

Minor trauma injuries (1)

Minor trauma injuries (1)

Chest Pain (3)

Loss of consciousness (5)

Irrelevant 
Minor Trauma Injuries (1)

16. Diabetes

Others (9)

17. Diarrhea and vomiting

Abdominal pain (8)

18. Ear problems

Others (9)

19. Exposure to chemicals

Minor Trauma Injuries (1)

20. Facial problems

Minor Trauma Injuries (1)

21. Falls

Minor Trauma Injuries (1)

22. Fits

Loss of consciousness (5)

23. Foreign body

Minor Trauma Injuries (1)

24. Gl bleeding

Abdominal pain (8)

25. Headache

Others (9)

26. Head injury

Minor trauma Injuries (1)

27. Irritable child

Irrelevant

28. Limb problems

Minor Trauma Injuries (1)

29. Limping child

Irrelevant

30. Major trauma

Major Trauma Injuries (2)

31. Mental illness

Mental Health Problems (6)

32. Neck pain

Others (9)

33. Overdose and poisoning

Mental Health Problems (6)

34. Palpitations

Chest pain (3)

35. Pregnancy

Others (9)

36. Psychiatric Illness

Mental Health Problems (6)

37. PV bleeding

Others (9)

38. Rashes

Others (9)

39. Self-harm

Mental Health Problems (6)

40. Sexually acquired infection

Others (9)

41. Shortness of breath in adults

Dyspnea (4)

42. Shortness of breath in children

Irrelevant

43. Sore throat

Others (9) 

44. Testicular pain
Others (9)
45. Torso injury
Minor Trauma Injuries (1)
46. Unwell adult
Malaise (7)
47. Unwell child
Irrelevant
48. Urinary problems
Others (9)
49. Worried parent
Others (9)
50. Wounds
Minor Trauma Injuries (1)
51. Major incidents-primary
Major Trauma injuries (2)
52. Major incidents secondary
Major Trauma injuries (2) 


\section{Systolic BP, $\mathrm{mmHg}^{2}$}

$44 \mathrm{O}_{2}$ saturation, $\%^{3}$ median, IQR

45 Temperature, ${ }^{\circ} \mathrm{C}^{4}$

46

4

48

49 Performed test, $\boldsymbol{n}$ (\%)

50 Phlebotomised blood sample $\quad 4714$ (54.0)

$\begin{array}{cccccc}922(10.6) & 873(10.4) & 0.693 & 247(11.9) & 243(11.7) & 0.892 \\ & & 0.040 & & & 0.263 \\ 3656(42.2) & 3301(39.6) & & 621(30.1) & 641(31.2) & \\ 183(2.1) & 208(2.5) & & 32(1.5) & 28(1.4) & \\ 980(11.3) & 992(11.9) & & 302(14.6) & 329(16.0) & \\ 426(4.9) & 394(4.7) & & 221(10.7) & 179(8.7) & \\ 219(2.5) & 241(2.9) & & 118(5.7) & 100(4.9) & \\ 219(2.5) & 230(2.8) & & 34(1.6) & 26(1.3) & \\ 1032(11.9) & 1034(12.4) & & 377(18.3) & 403(19.6) & \\ 935(10.7) & 922(11.1) & & 183(8.9) & 183(8.9) & \\ 1018(11.7) & 1019(12.2) & & 177(8.6) & 164(8.0) & \\ & & & & & \\ 136(21.4) & 135(21.5) & 0.021 & 145(27) & 145(28) & 0.566 \\ 98(98-100) & 99(97-100) & <0.001 & 98(96-100) & 98(96-99) & 0.100 \\ 37.0(0.8) & 37.0(0.8) & 0.065 & 36.9(1.0) & 36.9(0.9) & 0.913 \\ 17.6(4.6) & 17.6(4.8) & 0.875 & 18.7(5.5) & 18.6(5.4) & 0.666 \\ 86(20) & 86(21) & 0.783 & 84(20) & 84(21) & 0.982\end{array}$

Temperature measured in degrees Celsius. Heart rate and respiratory rate are measured as times per minute.

d) Number of measured values per age group.

$<70$ years: $1: n=17009,2: n=9924,3: n=10018,4: n=9953,5: n=5807,6: n=10371$

$>70$ years: $1: n=4118,2: n=3232,3: n=3208,4: n=2890,5: n=2302,6: n=3292$

e) $\quad$ values are measured by t-test for scale values and chi-square for categorical values. Mann-Whitney $\mathrm{U}$ test for non-parametric variables. 
Supplemental table 2: Univariable association of predictors of hospitalization of patients aged younger and older than 70 years at the emergency department - derivation cohort

\begin{tabular}{|c|c|c|c|c|c|c|c|c|c|}
\hline \multirow{3}{*}{$\begin{array}{l}\text { Predictor } \\
\text { Age/10 }\end{array}$} & \multicolumn{4}{|c|}{$\begin{array}{c}<70 \text { years } \\
n=8728\end{array}$} & \multicolumn{4}{|c|}{$\begin{array}{c}\geq 70 \text { years } \\
n=2079\end{array}$} & \multirow[t]{3}{*}{$\begin{array}{c}\text { P for } \\
\text { interaction }\end{array}$} \\
\hline & \multirow[t]{2}{*}{ n (\%) } & \multirow{2}{*}{$\begin{array}{c}\text { OR } \\
1.42\end{array}$} & \multicolumn{2}{|c|}{$95 \% \mathrm{Cl}$} & \multirow[t]{2}{*}{ n (\%) } & \multirow{2}{*}{$\begin{array}{c}\text { OR } \\
1.06\end{array}$} & \multicolumn{2}{|c|}{$95 \% \mathrm{Cl}$} & \\
\hline & & & 1.37 & 1.47 & & & 0.93 & 1.22 & \\
\hline Sex & & & & & & & & & 0.071 \\
\hline Male & 4762 (54.6) & 1.11 & 1.00 & 1.22 & 995 (47.9) & 1.33 & 1.12 & 1.58 & \\
\hline Female & 3966 (45.4) & ref & ref & ref & 1084 (52.1) & ref & ref & ref & \\
\hline Triage category & & & & & & & & & $<0.001$ \\
\hline$>1$ hour & 3240 (37.1) & ref & ref & ref & $479(23.0)$ & ref & ref & ref & \\
\hline$<1$ hour & 3567 (40.9) & 5.55 & 4.73 & 6.52 & $943(45.4)$ & 3.03 & 2.34 & 3.92 & \\
\hline$<10 \min$ & $1921(22.0)$ & 12.13 & 10.24 & 14.36 & $657(31.6)$ & 5.57 & 4.25 & 7.31 & \\
\hline Arrival mode & & & & & & & & & $<0.001$ \\
\hline Self- referral & 4258 (48.8) & ref & ref & ref & $467(22.4)$ & ref & ref & ref & \\
\hline Referred & 3154 (36.1) & 2.28 & 2.03 & 2.56 & 1016 (48.9) & 1.33 & 1.06 & 1.67 & \\
\hline Ambulance & $1316(15.1)$ & 4.08 & 3.55 & 4.70 & $596(28.7)$ & 1.99 & 1.55 & 2.55 & \\
\hline Chief Complaint & & & & & & & & & $<0.001$ \\
\hline Minor trauma & 3656 (42.2) & ref & ref & ref & $321(30.1)$ & ref & ref & ref & \\
\hline Major trauma & $183(2.1)$ & 9.15 & 6.67 & 12.55 & $32(1.5)$ & 5.28 & 2.49 & 11.18 & \\
\hline Chest pain & $980(11.3)$ & 3.33 & 2.75 & 4.04 & $302(14.6)$ & 1.12 & 0.82 & 1.52 & \\
\hline Dyspnea & $426(4.9)$ & 9.31 & 7.42 & 11.67 & $221(10.7)$ & 3.80 & 2.76 & 5.24 & \\
\hline Syncope & $219(2.5)$ & 6.52 & 4.82 & 8.81 & $119(5.7)$ & 2.33 & 1.56 & 3.49 & \\
\hline Psychiatric & $219(2.5)$ & 8.54 & 6.36 & 11.46 & $34(1.6)$ & 4.46 & 2.19 & 9.12 & \\
\hline Malaise & 1032 (11.9) & 11.34 & 9.55 & 13.46 & $377(18.3)$ & 4.90 & 3.72 & 6.45 & \\
\hline Abdominal pain & 935 (10.8) & 6.83 & 5.70 & 8.17 & $183(8.9)$ & 3.48 & 2.47 & 4.90 & \\
\hline Other & 1018 (11.7) & 3.14 & 2.59 & 3.80 & $177(8.6)$ & 2.08 & 1.47 & 2.94 & \\
\hline Type of specialist & & & & & & & & & $<0.001$ \\
\hline Medicine & 3809 (43.6) & 3.83 & 3.44 & 4.26 & $1251(60.2)$ & 2.44 & 2.03 & 2.94 & \\
\hline Surgery & 4919 (56.4) & ref & ref & ref & 828 (39.8) & ref & ref & ref & \\
\hline Revisit to the ED & $922(10.6)$ & 1.99 & 1.72 & 2.31 & 247 (11.9) & 1.51 & 1.16 & 1.97 & 0.074 \\
\hline $\begin{array}{l}\text { Phlebotomised } \\
\text { blood sample }\end{array}$ & 4714 (54.0) & 14.74 & 12.49 & 17.38 & $1606(77.2)$ & 12.80 & 9.09 & 18.02 & 0.467 \\
\hline $\begin{array}{l}\text { Oxygen } \\
\text { saturation }\end{array}$ & & & & & & & & & 0.005 \\
\hline$\leq 90 \%$ & $57(0.7)$ & 4.19 & 2.39 & 7.35 & $53(2.5)$ & 6.93 & 3.11 & 15.45 & \\
\hline $91-94 \%$ & $188(2.2)$ & 2.91 & 2.16 & 3.92 & $126(6.1)$ & 2.19 & 1.48 & 3.22 & \\
\hline$\geq 95 \%$ & 4755 (54.5) & ref & ref & ref & 1403 (67.5) & ref & ref & ref & \\
\hline Missing & 3728 (42.7) & 0.13 & 0.12 & 0.15 & 497 (23.9) & 0.21 & 0.17 & 0.28 & \\
\hline Systolic BP & & & & & & & & & 0.007 \\
\hline$\leq 100$ & $146(1.7)$ & 2.96 & 2.11 & 4.15 & 61 (2.9) & 2.27 & 1.30 & 3.97 & \\
\hline 101-199 & $4813(55.1)$ & ref & ref & ref & $1468(70.6)$ & ref & ref & ref & \\
\hline$>200$ & $47(0.5)$ & 1.76 & 0.99 & 3.13 & 60 (2.9) & 0.89 & 0.53 & 1.49 & \\
\hline Missing & 3722 (42.6) & 0.11 & 0.09 & 0.13 & $490(23.6)$ & 0.17 & 0.13 & 0.22 & \\
\hline Temperature & & & & & & & & & 0.004 \\
\hline$\leq 35.0$ & $36(0.4)$ & 2.68 & 1.39 & 5.19 & $22(1.1)$ & 1.83 & 0.76 & 4.39 & \\
\hline $35.1-38.4$ & 4471 (51.2) & ref & ref & ref & 1307 (62.9) & ref & ref & ref & \\
\hline$\geq 38.5$ & $288(3.3)$ & 7.51 & 5.65 & 9.99 & $105(5.1)$ & 7.40 & 4.10 & 13.36 & \\
\hline Missing & 3933 (45.1) & 0.21 & 0.18 & 0.24 & 645 (31.0) & 0.33 & 0.26 & 0.40 & \\
\hline Heart rate & & & & & & & & & \\
\hline$\leq 50$ & $63(0.7)$ & 0.80 & 0.46 & 1.40 & 31 (1.5) & 1.87 & 0.89 & 3.93 & \\
\hline
\end{tabular}


2

3

\begin{tabular}{|c|c|c|c|c|c|c|c|c|c|}
\hline $51-100$ & $4098(47.0)$ & ref & ref & ref & 1308 (62.9) & ref & ref & ref & \\
\hline $101-110$ & $456(5.2)$ & 1.85 & 1.52 & 2.25 & $115(5.5)$ & 1.72 & 1.16 & 2.55 & \\
\hline $111-129$ & $395(4.5)$ & 2.51 & 2.04 & 3.09 & 95 (4.6) & 1.76 & 1.15 & 2.71 & \\
\hline$\geq 130$ & 166 (1.9) & 3.05 & 2.22 & 4.18 & $65(3.1)$ & 1.06 & 0.64 & 1.74 & \\
\hline Missing & 3550 (40.7) & 0.12 & 0.10 & 0.14 & 465 (22.4) & 0.18 & 0.13 & 0.23 & \\
\hline Respiratory rate & & & & & & & & & 0.048 \\
\hline$\leq 8$ & $8(0.1)$ & 1.12 & 0.26 & 4.70 & $3(0.1)$ & 2.16 & 0.19 & 24.12 & \\
\hline $9-14$ & 726 (8.3) & ref & ref & ref & $237(11.4)$ & ref & ref & ref & \\
\hline $15-20$ & 1566 (17.9) & 1.09 & 0.91 & 1.31 & $584(28.1)$ & 1.04 & 0.77 & 1.40 & \\
\hline $21-29$ & 517 (5.9) & 1.78 & 1.42 & 2.24 & $273(13.1)$ & 1.96 & 1.37 & 2.79 & \\
\hline$\geq 30$ & 78 (0.9) & 8.50 & 4.67 & 15.45 & $57(2.7)$ & 6.61 & 3.00 & 14.56 & \\
\hline Missing & $5833(66.8)$ & 0.32 & 0.27 & 0.38 & $925(44.5)$ & 0.45 & 0.33 & 0.60 & \\
\hline $\begin{array}{ll}\text { a) Abbreviation } & \text { Age in years } \\
\text { b) } & \text { Vital parame } \\
\text { c) } & \text { millimeters } \\
\text { d) } & \text { P-for interac }\end{array}$ & $\begin{array}{l}\text { number, OR: odd } \\
\text { ded by ten. } \\
\text { measured are: ox } \\
\text { ercury. Temperatc }\end{array}$ & & & & iratory rate ar & & & $\begin{array}{l}\text { essure, } r \\
\text { ute. }\end{array}$ & \\
\hline
\end{tabular}


Supplemental table 3: Complete multivariable model of hospitalization of patients at the Emergency Department derivation cohort.

$<70$ years $\quad \geq 70$ years

10 Sex

11

12

12

13 Triage category

14

15

$16<1$ hour

$17<10 \mathrm{~min}$

18 Arrival mode

19

(2)

2

23 Chief Complaint

Minor trauma

25 Major trauma

26 Chest pain

Self- referral

Referred

OR $\quad 95 \% \mathrm{Cl}$

P-value

$95 \% \mathrm{Cl}$

1.31

P value

7 Dyspnea

$\begin{array}{llll}1.25 & 1.19 & 1.30 & <0.001\end{array}$

OR

0.226

$\begin{array}{llll}1.25 & 1.11 & 1.42 & <0.001\end{array}$

1.01

0.82

1.25

0.918

ref ref ref ref

ref

ref ref

ref

$\begin{array}{cccccccc}\text { ref } & \text { ref } & \text { ref } & \text { ref } & \text { ref } & \text { ref } & \text { ref } & \text { ref } \\ 2.22 & 1.85 & 2.67 & <0.001 & 1.70 & 1.26 & 2.31 & 0.001 \\ 3.64 & 2.93 & 4.52 & <0.001 & 3.09 & 2.14 & 4.45 & <0.001\end{array}$

28 Syncope

29 Psychiatric

ref

30 Malaise

$\begin{array}{cc}\text { ref } & \text { ref } \\ 1.21 & 1.05\end{array}$

ref ref

ref
1.09

ref ref

ref

$\begin{array}{llll}1.94 & 1.63 & 2.32 & <0.001\end{array}$

1.40

$0.82 \quad 1.45$

0.541

ref ref ref

$\begin{array}{lll}1.31 & 0.89 & 1.94\end{array}$

ref ref

0.28

$0.21 \quad 0.36$

0.171

ref

$1.03 \quad 1.91$

0.030

0.79

$0.58 \quad 1.07$

$<0.001$

0.94

ref

ref

ref

$\begin{array}{lll}0.74 & 0.51 & 1.06\end{array}$

0.128

0.40

2.18

0.881

0.19

0.12

0.30

$<0.001$

1.48

0.099

0.48

0.25

0.67

$<0.001$

1.19

0.53

0.004

1.31

0.026

0.83

0.668

1.34

$1.03 \quad 1.66$

1.22

0.74

0.316

1.13

1.07

1.12

0.80

1.69

0.600

32 Other

33 Type of specialist

34 Medicine

35 Surgery

$\begin{array}{llll}1.17 & 0.99 & 1.37 & 0.062\end{array}$

1.10

0.81

1.94

0.342

ref ref ref ref

ref

$\begin{array}{llll}1.57 & 1.32 & 1.88 & <0.001\end{array}$

1.95

ref

1.49

0.526

$\begin{array}{llll}4.79 & 3.83 & 5.99 & <0.001\end{array}$

7.25

1.41

ref

ref

37

38 Phlebotomised

39 blood sample

40 Oxygen saturation

41

$\leq 90 \%$

91-94\%

$\geq 95 \%$

$44 \quad$ Missing

45 Systolic BP

4

49

5

5

5

5

5

58

59

6

$$
\begin{aligned}
& \leq 100 \\
& 101-199
\end{aligned}
$$

$>200$

Missing

mperature

$\leq 35.0$

35.1-38.4

$\geq 38.5$

Missing

$\leq 50$

$\leq 50$

$51-100$

$101-110$

111-129

$\geq 130$

Missing

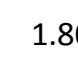

1.78

ref

1.11

$\begin{array}{llll}1.96 & 1.33 & 2.88 & 0.001\end{array}$

ref ref ref ref

$\begin{array}{llll}1.32 & 0.70 & 2.47 & 0.386\end{array}$

0.57

$\begin{array}{lll}0.40 & 0.82 & 0.002\end{array}$

4.76

2.69

$<0.001$

$<0.001$

$\begin{array}{llll}1.86 & 0.89 & 3.87 & 0.099\end{array}$

ref ref ref ref

$\begin{array}{llll}3.34 & 2.41 & 4.61 & <0.001\end{array}$

4.42

1.83

10.68

0.001

$1.58 \quad 1.02$

2.47

0.042

ref ref ref ref

$\begin{array}{llll}1.25 & 0.68 & 2.29 & 0.475\end{array}$

0.85

$\begin{array}{lll}0.70 & 1.02 & 0.083\end{array}$

1.70

0.92

3.13

0.091

ref ref ref ref

$\begin{array}{lll}0.71 & 0.39 & 1.28\end{array}$

0.259

0.59

0.31

1.11

0.103

$\begin{array}{llll}0.67 & 0.36 & 1.26 & 0.214\end{array}$

0.91

0.34

2.41

0.844

ref ref ref ref

3.36

1.78

6.36

$<0.001$

$\begin{array}{llll}0.94 & 0.70 & 1.27 & 0.691\end{array}$

ref ref ref

2.07

0.90

4.76

0.086

$\begin{array}{lll}1.62 & 1.29 & 2.03\end{array}$

$<0.001$

ref ref

ref

ref

$\begin{array}{lll}1.57 & 1.22 & 2.02\end{array}$

$<0.001$

1.35

0.86

2.11

0.196

$\begin{array}{lll}2.57 & 1.76 & 3.74\end{array}$

$<0.001$

0.76

$0.73 \quad 1.98$

0.471

1.07

$0.69 \quad 1.68$

0.753

0.81

$0.41 \quad 1.39$

0.369

$0.39 \quad 1.70$

0.577 
Supplemental table 4: Multivariable model of hospitalization of patients at the Emergency Department - training and test cohort 7
8 8 Predictor $<70$ years

9 Age/10
10 Sex 11 12

13 13 Triage category

15
$16<1$ hour $17<10 \mathrm{~min}$ 18 Arrival mode 19 2 23 Main Complaint

24 Minor trauma

25 Major trauma

26 Chest pain

27 Dyspnea

28 Collaps

29 Psychiatric

30 Malaise

31 Abdominal pain

32 Other

33 Type of specialist

34 Medicine

35 Surgery

36 Revisit to the ED

38 Phlebotomised

39 blood sample 40 Oxygen sturation

41

4

42

43

4

4

4

4
4
4

48

4

50

5

91-94\%

$$
\geq 95 \%
$$

Missing

5 Systolic BP

$\leq 100$

101-199

$>200$

Missing

Temperature

$<35.0$

35.1-38.4

$\geq 38.5$

Missing

6 Heart rate

$58 \quad 51-100$

$59 \quad 101-110$

$60 \quad 111-129$

$\geq 130$

$\begin{array}{ccc}0.655 & 1.93 & 1.00 \\ 0.387 & 1.47 & \begin{array}{c}1.05 \\ \text { ref }\end{array} \\ 0.090 & 1.09 & 0.78 \\ & & \\ 0.802 & 2.23 & 1.52 \\ \text { ref } & \text { ref } & \text { ref } \\ 0.243 & 1.28 & 0.67 \\ -0.453 & 0.64 & 0.46 \\ & & \\ 0.225 & 1.25 & 0.58 \\ \text { ref } & \text { ref } & \text { ref } \\ 1.356 & 3.88 & 2.79 \\ -0.041 & 0.96 & 0.80 \\ & & \\ 0.095 & 1.10 & 0.64 \\ \text { ref } & \text { ref } & \text { ref } \\ 0.458 & 1.58 & 1.26 \\ 0.417 & 1.52 & 1.17 \\ 0.620 & 1.86 & 1.27\end{array}$

$\begin{array}{cc}3.72 & 0.051 \\ 2.07 & 0.025 \\ \text { ref } & \text { ref } \\ 1.53 & 0.600\end{array}$

1.482

1.55

12.48

0.005

$0.216 \quad 1.24$

0.83

1.86

0.294

ref ref ref

ref

ref

$3.27<0.001$

$\begin{array}{ccccc}\text { ref } & \text { ref } & \text { ref } & \text { ref } & \text { ref } \\ 0.137 & 1.15 & 0.78 & 1.69 & 0.486 \\ -1.534 & 0.22 & 0.16 & 0.28 & <0.001 \\ -0.576 & 0.56 & 0.41 & 0.77 & <0.001 \\ -0.332 & 0.72 & 0.51 & 1.02 & 0.065 \\ 0.284 & 1.33 & 0.93 & 1.91 & 0.123 \\ 0.134 & 1.14 & 0.90 & 1.46 & 0.276 \\ 0.111 & 1.12 & 0.89 & 1.41 & 0.351 \\ -0.046 & 0.96 & 0.75 & 1.23 & 0.717 \\ & & & & \\ 0.344 & 1.41 & 1.20 & 1.67 & <0.001 \\ \text { ref } & \text { ref } & \text { ref } & \text { ref } & \text { ref }\end{array}$

$0.032 \quad 1.03$

0.58

1.85

0.914

$\begin{array}{ccccc}0.802 & 2.23 & 1.52 & 3.27 & <0.001 \\ \text { ref } & \text { ref } & \text { ref } & \text { ref } & \text { ref }\end{array}$

$\begin{array}{lllll}0.243 & 1.28 & 0.67 & 2.43 & 0.462\end{array}$

$\begin{array}{lll}0.46 & 0.89 & 0.008\end{array}$

$2.72 \quad 0.571$

$2.72 \quad 0.571$

ref ref

$-0.017 \quad 0.98$

0.38

2.52

0.971

$5.40<0.001$

ref

ref

ref

ref

ref

$1.16 \quad 0.668$

1.688
-0.228

5.41

2.61

11.23

$<0.001$

$1.89 \quad 0.729$

ref ref

0.713

2.04

0.59

1.08

0.137

$1.99<0.001$

ref

0.90

4.63

0.088

$1.97 \quad 0.002$

$-0.030$

ref

ref

ref

ref

$2.72 \quad 0.001$

0.105

1.11

0.64

1.47

0.888

$-0.740 \quad 0.48$

0.26

1.79

0.667

0.02 
3

4

\begin{tabular}{|c|c|c|c|c|c|c|c|c|c|c|}
\hline $\begin{array}{l}\text { Missing } \\
\text { Respiratory rate }\end{array}$ & -0.106 & 0.90 & 0.58 & 1.40 & 0.638 & -0.324 & 0.72 & 0.38 & 1.39 & 0.328 \\
\hline$\leq 8$ & -0.840 & 0.43 & 0.09 & 1.98 & 0.280 & 21.663 & $\infty$ & 0 & $\infty$ & 0.999 \\
\hline $9-14$ & ref & ref & ref & ref & ref & ref & ref & ref & ref & ref \\
\hline $15-20$ & -0.026 & 0.97 & 0.80 & 1.20 & 0.802 & 0.189 & 1.21 & 0.87 & 1.68 & 0.261 \\
\hline $21-29$ & 0.352 & 1.42 & 1.09 & 1.86 & 0.010 & 0.630 & 1.88 & 1.26 & 2.79 & 0.002 \\
\hline$\geq 30$ & 1.220 & 3.39 & 1.79 & 6.41 & $<0.001$ & 1.073 & 2.93 & 1.38 & 6.20 & 0.005 \\
\hline Missing & -0.007 & 0.99 & 0.81 & 1.22 & 0.949 & -0.054 & 0.95 & 0.67 & 1.34 & 0.761 \\
\hline ntercept & -4.687 & & & & & -5.021 & & & & \\
\hline raining cohort & $0.86(0$. & . 87$)$ & & & & $0.80(0.7$ & .82) & & & \\
\hline
\end{tabular}

15 AUC (95\% Cl)

16 GoF-value

0.387

0.373

17 Test cohort AUC

$18(95 \% \mathrm{Cl})$

19 a) Abbreviations: n: number, OR: odds ratio, 95\%Cl: 95\% confidence interval. GoF= Hosmer-Lemeshow Goodness of Fit $\chi^{2}$ test. AUC: Area Under The Curve 20 b) Age in years divided by ten.

c) Vital parameters measured are:oxygen saturation, measured in percentage oxygenated hemoglobin. Systolic BP: Systolic blood pressure, measured in millimeters of mercury. Temperature measured in degrees Celsius. Heart rate and respiratory rate are measured as times per minute.

d) P-value values are derived from multiple logistic regression analysis. 
REBUTTAL

MS ID\#: emermed-2016-205846.R6

MS TITLE: Early prediction of hospital admission for emergency department patients, a comparison between patients younger or older than 70 -years.

Authors: Lucke, Jacinta; de Gelder, Jelle; Clarijs, Fleur; Heringhaus, Christian; de Craen, Anton; Fogteloo, Anne; Blauw, Gerard Jan; de Groot, Bas; Mooijaart, Simon

May 2017 


\section{Editor:}

Comments to the Author:

Thank you for your recent revision. Our remaining concern is about the exclusion for "unjustified ED visits."

\section{Question 1:}

First, we are very concerned that readers might not find the term "unjustified ED visits" acceptable and in conflict with permitting laypeople to decide their healthcare needs and priorities. This term needs to be removed from the paper. It is not necessary to label these visits but rather fully describe them, which leads to our second point.

\section{Answer 1:}

We will adjust this term, and change it to 'ED visits due to logistical reasons'

\section{Adjustment:}

'unjustified ED visits' changes into 'ED visits due to logistical reasons' throughout the manuscript.

Question 2: In your most recent reply to reviewers you state that the list included patients with: planned re-evaluation (e.g patients with a wound or abdominal pain that could not wait for the next available appointment in de out-patient clinic), visits to the ED because of lack of availability of time in the out-patient clinic, laboratory checks for logistical reasons, patients who were sent away from the ED to visit their GP etc (because a visit to the GP is approximately 350 euro's less expensive in the current Dutch health care system).

This list should be included in your Methods. Most of these seem reasonable exclusions in that the patients were either scheduled to be seen, the ED was presumably the only site to get labs, or they were not seen because they were sent to GP clinics. However, there is one group of patients who were seen by the ED but came because of lack of availability of time in the outpatient clinic. Why would these patients be excluded? In some cases, patients will present to an outpatient clinic and be sick enough to require admission. Please explain why you chose to exclude these patients and also how you were able to retrospectively identify them in your cohort. You should also tell us how many such patients there were - if only a few, this would not affect your results much, but if its the majority, this could have had an impact on your results.

\section{Answer 2:}

These patients were excluded because the ED is sometimes used as an alternative pathway to get patients into the outpatient clinic. For example, a patient calls from home to his/her medical specialist because of a non-urgent problem but there are no places on their scheduled consultation hour. The specialist sends the patient to the ED, and because the patient is in the ED, the scheduling of the consultation hour is re-arranged and a place in the outpatient clinic is created. These patients do not require ED care, but rather use a backdoor into the outpatient clinic. This is registered in the file of the patient in the free text of the 'reason for ED visit' section, therefore we were able to identify this retrospectively. As you can imagine, this can be undesirable course of action as a patient is registered in the ED but does not receive care there, however it was a common practice during the inclusion period.

In the same group we categorized patients with eye or ENT problems that were registered in the ED but were not treated in the ED. Because the eye and ENT specialists prefer to see the patients in the outpatient clinic (where they have additional material and personnel), these patients are not treated in the ED but go to the outpatient clinic immediately. However they are registered in the computer system as ED visitors, therefore for the this retrospective study we had to exclude them. A total of 415 patients were excluded for this reason, $1.5 \%$ of all registered ED visits in that year. 


\section{Adjustment:}

We will provide additional explanation about this exclusion in the method section. We feel that the exclusion of these patients is justified as they do not require ED care and are not a true part of the ED patient population. If they would be included this would only introduce bias as they contain many missing data (because they were not treated in the ED, their charts are empty and only contain the referral to the outpatient clinic) and do not have similar chances of hospital admission compared to patient who visit the ED due to an acute situation.

We hope this explanation is satisfactory and we can proceed to swift publication of this manuscript.

Kind regards on behalf of the authors,

Jacinta Lucke 